\title{
Density-dependent processes in the transmission of human onchocerciasis: relationship between the numbers of microfilariae ingested and successful larval development in the simuliid vector
}

\author{
M. G. BASÁÑEZ $Z^{1, i *}$ J. H. F. REMME ${ }^{2}$, E. S. ALLEY $Y^{3}$, O. BAIN ${ }^{4}$, A. J. SHELLEY, \\ G. F. MEDLEY and R. M. ANDERSON \\ ${ }^{1}$ Department of Biology, Imperial College of Science, Technology and Medicine, Prince Consort Road, \\ London $S W 72 B B, U K$ \\ ${ }^{2}$ UNDP/World Bank/WHO Special Programme for Research and Training in Tropical Diseases, World Health \\ Organization, 20 Av. Appia, CH-1211 Geneva 27, Switzerland \\ ${ }^{3}$ Onchocerciasis Control Programme in West Africa, P.O. Box 549, Ouagadougou, Burkina Faso \\ ${ }^{4}$ Muséum d'Histoire Naturelle, 61 rue Buffon 75231, Paris Cedex 05, France \\ ${ }^{5}$ Natural History Museum, Cromwell Road, London SW7 5BD, UK \\ ${ }^{6}$ Department of Biological Sciences, University of Warwick, Coventry CV4 7AL, UK \\ 'Department of Zoology, University of Oxford, South Parks Road, Oxford OX1 3PS, UK
}

(Received 27 Yuly 1994; revised 7 October 1994; accepted 7 October 1994)

SUMMARY

A previous paper reported that the intake of Onchocerca volvulus microfilariae ( $\mathrm{mff}$ ) by different species of Simulium is essentially proportional to the parasite load in the skin of infected carriers. This paper examines the fate of the ingested $\mathrm{mff}$ in susceptible vectors to assess the relationship between parasite intake and infective larval output in blackfly species with and without well-developed cibarial armatures. Analysis is based on data from 3 onchocerciasis endemic areas: Guatemala (S. ochraceum s.l.), West Africa ( $S$. damnosum s.l./S. sirbanum) and the Amazonian focus between South Venezuela and Northern Brazil (S. guianense and S. oyapockense s.l.). The data, which include published and unedited information collected in the field, record experimental studies of parasite uptake by wild flies maintained in captivity until the completion of the extrinsic incubation period. The relationship between L3 output (measured as the mean number of successful larvae/fly or, as the proportion of flies with infective larvae) and average microfilarial intake, was strongly non-linear. This non-linearity was best represented by a sigmoid function in case of armed simuliids ( $S$. ochraceum s.l., S. oyapockense s.l.), or by a hyperbolic expression in that of unarmed flies (S. damnosum s.l., S. guianense). These results are compatible, respectively, with the patterns of 'initial facilitation' and 'limitation' described in culicid vectors of lymphatic filariases. A maximum mean number of 1-3 L3/fly was observed in all 4 vectors. It is concluded that $O$. volvulus larval development to the infective stage is regulated by density-dependent mechanisms acting at the early phase of microfilarial migration out of the blackfly's bloodmeal. Damage by the bucco-pharyngeal armature may also be density dependent. A hypothesis, based on this density dependence is forwarded to explain initial facilitation, so far only recorded in vectors with well-developed cibarial teeth. Our results provide quantitative support for the conjecture that chemotherapy alone is likely to have a greater impact on reducing onchocerciasis transmission in endemic areas where the main vector has a toothed fore-gut than in foci where the vectors have unarmed cibaria.

Key words: Onchocerca volvulus, simuliid vectors, larval development, density dependence, limitation, facilitation.

\section{INTRODUCTION}

The life-cycle of filarial nematodes consists of populations of parasites within the vertebrate host and the insect host, linked by parasite stages transmitted in both directions. The regulation of these parasite populations is mediated by densitydependent mechanisms acting at one or several points of the two-host life cycle (Dietz, 1982; Plaisier et al. 1990, 1991).

* Reprint requests to María-Gloria Basáñez, Department of Zoology, University of Oxford, South Parks Road, Oxford OX1 3PS.
The demographic dynamics of macroparasites such as the filarial worms depends on the magnitudes of the birth, death, immigration and emigration rates within either or both hosts (Anderson \& Gordon, 1982). Reproduction takes place only in the definitive host and there is no direct multiplication of parasites within either vertebrate or vector host. Density dependence translates into one or more of these rates being a function of the population density of the appropriate parasite stages (Dietz, 1988). This function may result in decreasing (negative feedback) or increasing (positive feed-back) rates of population growth as density rises. Although only negative feed-back processes are instrumental in 
Table 1. Sources of data used in this work

\begin{tabular}{|c|c|c|c|c|}
\hline Vector species & Locality & $\begin{array}{l}\text { Successful } \\
\text { larvae }\end{array}$ & $\begin{array}{l}\text { Type of } \\
\text { mean used }\end{array}$ & References \\
\hline Simulium ochraceum s.l. & Guatemala & $\begin{array}{l}\text { L3 } \\
\text { Hmcl.* or } \\
\text { Thor. } \dagger \mathrm{mff} \\
\text { Thor. mff and } \\
\text { L3 }\end{array}$ & $\begin{array}{l}\text { WM } \\
\text { SQRTM } \\
\text { SQRTM } \\
\text { SQRTM }\end{array}$ & $\begin{array}{l}\text { De León \& Duke (1966) } \\
\text { Bain, Durette-Desset \& } \\
\text { De León (1974) } \\
\text { Omar \& Garms (1975) } \\
\text { Collins et al. }(1977)\end{array}$ \\
\hline $\begin{array}{l}\text { Simulium damnosum s.l. (savanna spp.): } \\
\text { S. damnosum s.s. and S. sirbanum }\end{array}$ & $\begin{array}{l}\text { West Africa: } \\
\text { Upper Volta } \\
\text { Côte d'Ivoire } \\
\text { Southern Ghana }\end{array}$ & $\begin{array}{l}\text { L3 } \\
\text { Hmcl. or } \\
\text { Thor. mff } \\
\text { Hmcl. mff }\end{array}$ & $\begin{array}{l}\text { WM } \\
\text { AM§ } \\
\text { AM§ } \\
\text { AM } \\
\text { AM }\end{array}$ & $\begin{array}{l}\text { De León \& Duke (1966) } \\
\text { Bain (1971) } \\
\text { Philippon \& Bain (1972) } \\
\text { Philippon (1977) } \\
\text { OCP (1989) } \\
\text { Alley et al. (1994) }\end{array}$ \\
\hline Simulium guianense & Southern Venezuela & $\begin{array}{l}\text { Thor. mff and } \\
\text { L3 }\end{array}$ & $\begin{array}{l}\text { SQRTM§ } \\
\text { SQRTM§ }\end{array}$ & $\begin{array}{l}\text { Takaoka et al. }(1984 b) \\
\text { This work }\end{array}$ \\
\hline Simulium oyapockense s.l. & $\begin{array}{l}\text { Southern Venezuela } \\
\text { Northern Brazil }\end{array}$ & $\begin{array}{l}\text { Thor. mff and } \\
\text { L3 } \\
\text { Thor. larvaet } \\
\text { and L3 }\end{array}$ & $\begin{array}{l}\text { SQRTM§ } \\
\text { SQRTM§ }\end{array}$ & $\begin{array}{l}\text { This work } \\
\text { Shelley et al. (1987) }\end{array}$ \\
\hline
\end{tabular}

* Haemocoelic microfilariae. Calculated from flies dissected between 0.5 and $12 \mathrm{~h}$ p.e. (see text).

$\dagger$ Thoracic microfilariae. Calculated from flies dissected between 0.5 and $12 \mathrm{~h}$ p.e. (see text).

I Thoracic larvae, computed from flies dissected 24 h p.e. (see text).

$\S$ Means calculated from raw data.

constraining population growth, positive feed-back may also play a role in population dynamics by enhancing the chances of otherwise inefficient transmission mechanisms (Hairston \& De Meillon, 1968).

In the part of the life-cycle taking place in the vector host, density dependence may act on the elements of vector competence (Spielman \& Rossignol, 1985; Dye 1992a). More specifically it may influence the input of microfilariae ( $\mathrm{mff}$ ) into the insects, the survival and development of the larvae throughout the extrinsic incubation period, and the output of infective (L3) stages. More indirectly, it may act by affecting the survival, behaviour, etc. of the vector. In the particular case of human onchocerciasis, a previous paper (Basáñez et al. 1994) explored the first component of the transmission of Onchocerca volvulus from the human host to the simuliid vector, i.e. the microfilarial intake by the flies from the skin of infected carriers. Data from three different endemic areas in Africa and Latin America showed an almost linear relationship between dermal and ingested parasites in the ranges of microfilarial loads explored. However, it has been observed that the numbers of larvae successfully developing to the infective stage in filariasis vectors generally do not increase in the same proportional fashion (Jordan \& Goatly, 1962; Obiamiwe, 1977; Rosen, 1955). On the contrary, in most cases, there is a significant loss of parasites throughout the period required for larval maturation.

Among the factors that can affect the survival and development of the parasites within the vector are (1) genetically determined host susceptibility or refractoriness to infection (Curtis \& Graves, 1983), (2) the damage caused to ingested parasites by the cibarial/buccopharyngeal armature of the flies when it is present (Coluzzi \& Trabucchi, 1968; Omar \& Garms, 1975; McGreevy et al. 1978; Reid, 1978, 1994), (3) the dynamics of formation and structure of the peritrophic membrane, secreted around the bloodmeal (Lewis, 1950, 1953 ; Duke \& Lewis, 1964; Reid \& Lehane, 1984; Miller \& Lehane, 1993) and (4) the mounting of specific and non-specific insect defences to parasite invasion (Townson \& Chaithong, 1991; Ham, 1992). Some or all of these factors may be influenced by the density of the corresponding parasite stages.

The study of the events involved in the passage of ingested $\mathrm{mff}$ towards the site of final larval development in several vectors has led to the recognition of 3 main patterns, for which the terms 'limitation', 'facilitation' and 'proportionality' have been coined. They refer, respectively, to the fraction of successful larvae relative to the total parasite intake being a decreasing, an increasing or a constant function of the number of mff ingested (Bain, 1971, 1976; Pichon, 1974; Pichon, Perrault \& Laigret, 1974; Prod'hon et al. 1980; Southgate \& Bryan, 1992). They correspond to negative feed-back (the rate of successful incorporation of larvae within the insects decreases with parasite intake), positive feedback (success increases along with density), and density independence respectively. In these studies, 'successful' mff have been defined as those larvae 
managing to get out of the bloodmeal into the haemocoele or into the fly's location where maturation occurs, or actually completing their development to the infective stage.

It has been suggested that the non-linearities inherent in the concept of 'facilitation' and 'limitation' may have different and important implications for the control of these infections by, respectively, creating or not creating a transmission threshold below which the parasite will not persist in the host population (Brengues \& Bain, 1972; Pichon et al. 1974; Bain, 1976; Webber, 1991 ; Southgate \& Bryan, 1992). Such ideas are somewhat speculative at present due to the lack of a quantitative model for the population dynamics of the lymphatic filarial worms in both the definitive and vector hosts (Dye, 1992b, 1994; Dye \& Williams, 1994). However, if these patterns are found to be equally applicable to the relationship $O$. volvulus-Simulium, a faster progress in testing these hypotheses could be made due to the more advanced stage of development of such models in human onchocerciasis (Dietz, 1982; Davies, Weidhaas \& Haile, 1987; Plaisier et al. 1990; Anderson \& May, 1991; Davies, 1993).

This paper investigates the evidence for and nature of density dependence in the second step of the incorporation of $O$. volvulus parasites by the simuliid vectors, namely, the rate at which $\mathrm{mff}$ from an infected bloodmeal succeed in reaching the fly's thoracic muscles, where they undergo further development. We examine several parasite-vector combinations present in endemic areas of human onchocerciasis. These combinations include vectors with well-developed cibarial teeth (S. ochraceum s.l. from Guatemala and S. oyapockense s.l. from the Venezuelan-Brazilian border) as well as species without such an armature ( $S$. damnosum s.l. from West Africa and S. guianense from South Venezuela). Analyses are based upon published and unpublished data sets, and on new field studies conducted in Latin America.

We present the analyses of three different types of data sets. First, the relationship is explored between the mean numbers of $\mathrm{mff}$ ingested and the resulting mean numbers of successful larvae in blackfly species with and without a cibarial armature. A functional relationship between microfilarial input and larval output is thus obtained. Second, the fraction of flies harbouring successful larvae for different mean successful larval loads is studied in order to obtain an estimate of the degree of larval aggregation among these flies. Third, these estimates of larval aggregation are used together with the functional relationships calculated previously in order to examine the prevalence of flies carrying successful larvae as a function of the mean microfilarial intake.

This procedure provides a way (1) to compare the output of successful larvae (measured as mean numbers per fly and as fractions of potentially infective flies) for different levels of microfilarial input in species possessing and not possessing cibarial teeth, (2) to investigate the resulting patterns and to compare them with those proposed by the hypotheses of limitation or facilitation and (3) since the approximate proportionality between parasite intake and dermal load has already been demonstrated (Campbell et al. 1980; Alley et al. 1994; Basáñez et al. 1994), to advance hypotheses about the efficacy of various control measures in areas with either type of vector.

\section{MATERIALS AND METHODS}

\section{Sources of data}

Table 1 summarizes the sources of data analysed in this paper and the criteria for success used in the different studies. The definition of the category 'successful larvae' comprises those mff that reach the haemolymph of the insect on their way to the thoracic muscles (haemocoelic $\mathrm{mff}$ ), those that actually penetrate the muscle cells (thoracic larvae) and those that manage to develop to the infective stage (L3).

\section{Parasitological and entomological procedures}

All the results presented here are based on flyfeeding experiments, in which samples of wild flies to the main local vector species were engorged to repletion on subjects harbouring different intensities of skin infection and who, consequently, provided the flies with different mean microfilarial intakes of the local population of $O$. volvulus.

Assessment of the number of mff ingested, in the haemocoele and in the thorax of the flies and of the proportion of flies with larvae. In the different studies, groups of wild flies were fed on particular body regions of the various subjects participating in the investigation in an attempt to reduce heterogeneity in the intakes. The results comprise the figures obtained for different individual carriers and/or different local parasite densities along the body of those carriers. The procedures for fly collection and dissection are the same as those described by Basáñez et al. (1994). A subsample of the flies fed on each volunteer was dissected between 0.5 and $12 \mathrm{~h}$ postengorgement (p.e.) in order to score the number of ingested parasites (total microfilarial count within the body of the insect), microfilarial migration out of the bloodmeal (those mff that escaped imprisonment by the peritrophic membrane and were found either in the haemocoele-haemocoelic mff-or in the thoracic muscles of the fly-thoracic $\mathrm{mff}-$ ), and the fraction of flies harbouring successful $\mathrm{mff}$ among those dissected. The period between $0 \cdot 5$ and $12 \mathrm{~h}$ p.e. was chosen because a feature present in the published data sets and in our own observations was that $\mathrm{mff}$ started to appear in the thorax about $0.5 \mathrm{~h}$ after the 
Table 2. Successful larvae of Onchocerca volvulus from different microfilarial intakes by Simulium ochraceum s.l. in Guatemala

\begin{tabular}{|c|c|c|c|c|c|c|}
\hline \multirow{2}{*}{$\begin{array}{l}\text { Study } \\
\text { participants } \\
\text { Patient } \\
\text { code no.t }\end{array}$} & \multicolumn{5}{|c|}{ Mean no. of larvae/fly* } & \multirow{2}{*}{$\begin{array}{l}\text { Prevalence } \\
\text { of flies with } \\
\text { successful } \\
\text { larvae } \\
(\%)\end{array}$} \\
\hline & $\begin{array}{l}\text { No. of } \\
\text { flies }\end{array}$ & $\begin{array}{l}\text { Ingested } \\
\mathrm{mff} \\
(x)\end{array}$ & $\begin{array}{l}\text { Thor. or } \\
\text { Hmcl. } \mathrm{mff} \\
(y)\end{array}$ & $\begin{array}{l}\text { No. of } \\
\text { flies }\end{array}$ & $\begin{array}{l}\text { L3 } \\
\text { larvae } \\
(y)\end{array}$ & \\
\hline \multirow[t]{2}{*}{ C1f } & 24 & $1 \cdot 70$ & 0.00 & & & 0.00 \\
\hline & & & & 38 & $0 \cdot 04$ & $5 \cdot 26$ \\
\hline \multirow[t]{2}{*}{$\mathrm{C} 2 \downarrow$} & 24 & $2 \cdot 60$ & $0 \cdot 00$ & & & 0.00 \\
\hline & & & & 48 & 0.02 & $2 \cdot 08$ \\
\hline \multirow[t]{2}{*}{ DIat } & 69 & $9 \cdot 00$ & 一 & & & - \\
\hline & & & & 68 & $0 \cdot 19$ & - \\
\hline \multirow[t]{2}{*}{ C3t } & 20 & $12 \cdot 50$ & $0 \cdot 00$ & & & 0.00 \\
\hline & & & & 53 & 0.02 & $1 \cdot 89$ \\
\hline \multirow[t]{2}{*}{$\mathrm{C} 4 \mathrm{f}$} & 20 & $24 \cdot 20$ & $0 \cdot 17$ & & & $15 \cdot 00$ \\
\hline & & & & 62 & $0 \cdot 17$ & 8.06 \\
\hline \multirow[t]{2}{*}{ C5t } & 15 & $26 \cdot 90$ & $0 \cdot 30$ & & & $20 \cdot 00$ \\
\hline & & & & 37 & $0 \cdot 12$ & $13 \cdot 51$ \\
\hline \multirow[t]{2}{*}{ C6t } & 20 & $43 \cdot 10$ & $0 \cdot 17$ & & & $20 \cdot 00$ \\
\hline & & & & 70 & $0 \cdot 17$ & $18 \cdot 57$ \\
\hline \multirow[t]{2}{*}{$\mathrm{C} 7 \mathrm{f}$} & 24 & $44 \cdot 70$ & 0.56 & & & $12 \cdot 50$ \\
\hline & & & & 65 & $0 \cdot 17$ & $9 \cdot 23$ \\
\hline \multirow[t]{2}{*}{$\mathrm{C} 8 \ddagger$} & 24 & $51 \cdot 10$ & $0 \cdot 30$ & & & $25 \cdot 00$ \\
\hline & & & & 53 & 0.51 & $32 \cdot 08$ \\
\hline \multirow[t]{2}{*}{$\mathrm{C} 9 \ddagger$} & 20 & $82 \cdot 20$ & 0.99 & & & $40 \cdot 00$ \\
\hline & & & & 44 & 1.04 & $27 \cdot 27$ \\
\hline Of & 25 & $91 \cdot 41$ & 1.41 & & & - \\
\hline \multirow{2}{*}{$\begin{array}{l}\text { B2 } 1 \S \\
\text { (Rodolfo) }\end{array}$} & 134 & 115.99 & 1.51 & & & $\overline{39} \cdot 38$ \\
\hline & & & & - & - & - \\
\hline \multirow[t]{2}{*}{ C10t } & 20 & $117 \cdot 80$ & $1 \cdot 76$ & & & 55.00 \\
\hline & & & & 47 & 1.69 & $53 \cdot 19$ \\
\hline \multirow[t]{2}{*}{ DIIt } & 67 & $170 \cdot 00$ & - & & & - \\
\hline & & & & 99 & $2 \cdot 07$ & - \\
\hline \multirow{2}{*}{$\underset{\text { (Feliciano) }}{\mathrm{B}}\rfloor \S$} & 14 & $222 \cdot 57$ & $1 \cdot 69$ & & & $64 \cdot 29$ \\
\hline & & & & - & - & - \\
\hline B1 $\underset{\text { (Aparicio) }}{\mathrm{B}}$ & 221 & $265 \cdot 84$ & $2 \cdot 43$ & - & & $\begin{array}{l}76.49 \\
-\quad\end{array}$ \\
\hline \multirow{2}{*}{ DI-bł } & 64 & $390 \cdot 00$ & - & & & - \\
\hline & & & & 70 & $2 \cdot 53$ & - \\
\hline
\end{tabular}

* See Table 1 for type of mean used.

† D: De León \& Duke (1966), B: Bain, Durette-Desset \& De León (1974),

O: Omar \& Garms (1975), C: Collins et al. (1977).

Body regions on which flies were fed as follows:

I Back, $\S$ Fore-arms.

infected meal. In those data sets in which microfilarial intakes were recorded immediately $(0 \mathrm{~h})$ after engorgement $(S$. oyapockense s.l. from northern Brazil), it was too early to detect any larvae outside the bloodmeal and therefore the figures shown for thoracic larvae were calculated from different subsamples of flies dissected at $24 \mathrm{~h}$ p.e.

Fly maintenance and dissection for the assessment of $L 3$ output. When infective larval loads and proportion of infective flies were to be recorded, the remaining insects collected from each participant were kept alive until the completion of the extrinsic incubation period (within 6-7 days p.e. depending on the conditions under which flies were maintained in captivity). Although the methods of post-prandial transportation and maintenance of flies were slightly different across studies, all shared the common procedures of collection of the simuliids in individual tubes generally lined with filter paper, provision of a single bloodmeal at the beginning of the experiment (the putative infected meal), more regular provision of sugar solution usually with antibiotics, and maintenance under relatively constant conditions of temperature, high humidity and darkness, achieved by keeping the insects inside insulated cages or iceboxes (Figueroa, Collins \& Kozek, 1977; Takaoka et al. 1982). The results presented here correspond to mean worm burdens and percentages of flies with total L3 larvae (from head, thorax and abdomen) harboured by specimens dissected from $144 \mathrm{~h}$ (6 days p.e.) onwards. It has been observed that 
Table 3. Successful larvae of Onchocerca volvulus from different microfilarial intakes by Simulium oyapockense s.l. in Southern Venezuelan and Northern Brazilian Amazonas

\begin{tabular}{|c|c|c|c|c|c|c|}
\hline \multirow{2}{*}{$\begin{array}{l}\text { Study } \\
\text { participants }\end{array}$} & \multicolumn{5}{|c|}{ Mean no. of larvae/fly* } & \multirow[b]{2}{*}{$\begin{array}{l}\text { Prevalence } \\
\text { of flies with } \\
\text { successful } \\
\text { larvae } \\
(\%)\end{array}$} \\
\hline & $\begin{array}{l}\text { No. of } \\
\text { flies }\end{array}$ & $\begin{array}{l}\text { Ingested } \\
\text { mff } \\
(x)\end{array}$ & $\begin{array}{l}\text { Thoracic } \\
\text { mff } \\
(y)\end{array}$ & $\begin{array}{l}\text { No. of } \\
\text { flies }\end{array}$ & $\begin{array}{l}\text { Thor. } \\
\text { larvae } \\
\text { or L3 } \\
(y)\end{array}$ & \\
\hline \multirow[t]{2}{*}{ Carroay-a ${ }^{4}$} & 41 & $4 \cdot 59$ & $0 \cdot 10$ & & & $4 \cdot 88$ \\
\hline & & & & $\begin{array}{l}46 \\
71\end{array}$ & $\begin{array}{l}0.09 \\
0.05\end{array}$ & $\begin{array}{l}4 \cdot 35 \\
4 \cdot 23\end{array}$ \\
\hline Parima $^{2,3}$ & 18 & $10 \cdot 90$ & $0 \cdot 11$ & - & - & $5 \cdot 56$ \\
\hline \multirow[t]{3}{*}{ Catrimani-a ${ }^{2}$} & 21 & $15 \cdot 70$ & - & & & \\
\hline & & & & 25 & 0.00 & $0-00$ \\
\hline & & & & 69 & $0 \cdot 27$ & $20 \cdot 29$ \\
\hline \multirow[t]{3}{*}{ Catrimani- $\mathrm{b}^{\mathbf{3}}$} & 22 & 25.09 & - & & & \\
\hline & & & & 11 & $0 \cdot 16$ & $9 \cdot 09$ \\
\hline & & & & 80 & $0 \cdot 13$ & $10 \cdot 00$ \\
\hline \multirow[t]{3}{*}{ Cauamé $^{2}$} & 26 & $34 \cdot 43$ & - & & & \\
\hline & & & & 19 & 0.00 & $0 \cdot 00$ \\
\hline & & & & 37 & 0.07 & $8 \cdot 11$ \\
\hline \multirow[t]{2}{*}{ Carroay- $b^{3}$} & 33 & $172 \cdot 46$ & $2 \cdot 46$ & & & $48 \cdot 48$ \\
\hline & & & & 62 & $1 \cdot 41$ & $46 \cdot 77$ \\
\hline
\end{tabular}

* See Table 1 for type of mean used. Body regions on which flies were fed as follows: $+{ }^{2}$ Shoulders and Back, ${ }^{3}$ Iliac zone and Buttocks, ${ }^{4}$ Calves. Catrimani and Cauamé from Shelley et al. (1987). Carroay and Parima from this work.

infective larvae can be recruited to the proboscis from any location in the insect during the blood feed (Duke, 1973; Philippon, 1977; Renz, 1987).

\section{Analysis of data}

Measures of the average number of larvae in the bloodmeal, in the haemocoele or thorax and of infective stages per $f y$. Due to the various ways mean intakes and mean larval loads per fly are reported in the data sources, it was not possible to select a single measure of central tendency. The means most widely used in the published literature were the arithmetic mean (AM), the geometric mean of Williams (WM) and the square root transformed mean (SQRTM). All of them are computed taking into account infected and uninfected specimens. The justification and conditions for their usage, as well as their formulae, have been described by Basáñez et al. (1994).

Since the mean numbers of successful larvae appeared to level off along with increasing microfilarial intakes in all data sets examined, the relationship between these two variables was explored by non-linear regression methods (Quasi-Newton and Simplex), with weighted least squares estimation of the parameters (weight $=$ no. flies in each subsample). These analyses were performed with CSS: Statistica (Complete Statistical System) software.

Prevalence versus intensity data. The results of the non-linear estimations were subsequently used to examine the relationship between the percentage of flies with successful larvae and the intensity of the initial input of $\mathrm{mff}$. The fraction of simuliids harbouring potential or realized infective stages can be related to the mean larval burden per fly $(y)$ by the following expression:

Proportion of infective flies $=1-\{1+y / k\}^{-k}$,

where $k$ varies inversely with the degree of larval aggregation in the flies. As $k \rightarrow \infty$ the distribution tends to Poisson, whilst as $k \rightarrow 0$ the distribution is highly contagious or aggregated (variance $\gg$ mean), and can be described in terms of the negative binomial (Anderson \& May, 1985).

The estimates of $k$ obtained by this fitting procedure can then be used to predict the prevalence of flies carrying successful larvae as a function of the mean microfilarial intake, assuming different functional relationships between the mean L3 output $(y)$ and the initial average input of $\mathrm{mff}(x)$ :

Proportion of infective flies $=1-\{1+y(x) / k\}^{-k}$, (2)

where $y(x)$ are the predictions of the different nonlinear regression models aforementioned. The computation of $k$ values and of their asymptotic confidence limits from prevalence-intensity data was performed by maximum likelihood estimation procedures (Cox \& Hinkley, 1974; Guyatt et al. 1990). Different assumptions about the relationship between the parameter $k$ and the mean were tested by 
Table 4. Successful larvae of Onchocerca volvulus from different microfilarial intakes by Simulium damnosum s.l. in West Africa

\begin{tabular}{|c|c|c|c|c|c|}
\hline \multirow{2}{*}{$\begin{array}{l}\text { Study participants } \\
\text { Patient code no. } \uparrow\end{array}$} & \multicolumn{4}{|c|}{ Mean no. of larvae/fly* } & \multirow{2}{*}{$\begin{array}{l}\text { Prevalence } \\
\text { of flies with } \\
\text { successful } \\
\text { larvae } \\
(\%)\end{array}$} \\
\hline & $\begin{array}{l}\text { No. of } \\
\text { fies }\end{array}$ & $\begin{array}{l}\text { Ingested } \\
\mathrm{mff} \\
(x)\end{array}$ & $\begin{array}{l}\text { Thor. or } \\
\text { Hmcl. mff } \\
(y)\end{array}$ & $\begin{array}{l}\text { L3 } \\
\text { larvae } \\
(y)\end{array}$ & \\
\hline OCP28 & 50 & 0.02 & 0.00 & & 0.00 \\
\hline OCP 37 & 50 & 0.30 & 0.08 & & $6 \cdot 00$ \\
\hline OCP41 & 50 & 0.48 & 0.04 & & $4 \cdot 00$ \\
\hline OCP46 & 50 & 0.66 & 0.00 & & 0.00 \\
\hline OCP56 & 50 & 0.84 & 0.02 & & $2 \cdot 00$ \\
\hline OCP54 & 50 & 0.90 & $0 \cdot 12$ & & $10 \cdot 00$ \\
\hline DD1 & 93 & $1 \cdot 10$ & - & 0.40 & - \\
\hline OCP17 & 50 & 1.82 & 0.14 & & $10 \cdot 00$ \\
\hline OCP55 & 50 & 1.96 & 0.24 & & $14 \cdot 00$ \\
\hline OCP47 & 50 & $2 \cdot 40$ & 0.30 & & 18.00 \\
\hline OCP18 & 52 & $2 \cdot 48$ & $0 \cdot 13$ & & 11.54 \\
\hline OCP57 & 50 & $2 \cdot 80$ & $0 \cdot 32$ & & $24 \cdot 00$ \\
\hline OCP39 & 50 & $4 \cdot 50$ & 0.26 & & 16.00 \\
\hline OCP49 & 50 & $5 \cdot 24$ & $0 \cdot 30$ & & $20 \cdot 00$ \\
\hline OCP36 & 50 & $6 \cdot 12$ & 0.46 & & $26 \cdot 00$ \\
\hline OCP53 & 50 & 6.50 & $0 \cdot 34$ & & $32 \cdot 00$ \\
\hline OCP20 & 50 & $7 \cdot 34$ & 0.46 & & $30 \cdot 00$ \\
\hline OCP34 & 50 & $9 \cdot 56$ & 0.50 & & $38 \cdot 00$ \\
\hline OCP26 & 50 & $10 \cdot 42$ & 0.44 & & 30.00 \\
\hline OCP21 & 50 & $12 \cdot 62$ & 0.44 & & $30 \cdot 00$ \\
\hline OCP33 & 50 & 13.54 & 0.36 & & $22 \cdot 00$ \\
\hline OCP 22 & 50 & $14 \cdot 32$ & 0.34 & & $28 \cdot 00$ \\
\hline OCP61 & 50 & 14.92 & 0.28 & & $18 \cdot 00$ \\
\hline OCP29 & 50 & 15.94 & 0.98 & & 50.00 \\
\hline OCP60 & 50 & $16 \cdot 20$ & 1.00 & & $56 \cdot 00$ \\
\hline OCP30 & 50 & $16 \cdot 56$ & 1.06 & & $42 \cdot 00$ \\
\hline OCP58 & 50 & $17 \cdot 16$ & 0.50 & & $30 \cdot 00$ \\
\hline OCP 40 & 50 & $19 \cdot 20$ & 0.66 & & $42 \cdot 00$ \\
\hline OCP35 & 50 & 21.88 & 0.68 & & 32.00 \\
\hline $\mathrm{PH}^{12}$ & 172 & $22 \cdot 31$ & 0.53 & & $29 \cdot 65$ \\
\hline OCP 23 & 50 & $25 \cdot 76$ & 0.40 & & $28 \cdot 00$ \\
\hline $\mathrm{PH}^{24}$ & 58 & 26.03 & 0.62 & & $31 \cdot 03$ \\
\hline OCP31 & 49 & $27 \cdot 27$ & 0.80 & & $42 \cdot 86$ \\
\hline OVP32 & 50 & $30 \cdot 24$ & $0 \cdot 64$ & & 36.00 \\
\hline OCP38 & 50 & $30 \cdot 32$ & $0 \cdot 86$ & & $42 \cdot 00$ \\
\hline OCP59 & 50 & $34 \cdot 26$ & 1.84 & & $44 \cdot 00$ \\
\hline $\mathrm{PH} 2 \mathrm{~b}^{12}$ & 308 & $38 \cdot 78$ & 0.56 & & $25 \cdot 00$ \\
\hline OCP19 & 50 & 43.68 & 1.00 & & $44 \cdot 00$ \\
\hline OCP45 & 50 & $43 \cdot 72$ & 1.58 & & 50.00 \\
\hline $\mathrm{PB}^{24}$ & 270 & $46 \cdot 10$ & $1 \cdot 81$ & & $41 \cdot 26$ \\
\hline $\mathrm{BA} 1^{12}$ & 102 & $50 \cdot 34$ & 1.56 & & 59.80 \\
\hline OCP42 & 50 & $50 \cdot 64$ & $1 \cdot 12$ & & 38.00 \\
\hline OCP43 & 50 & $58 \cdot 34$ & 1.00 & & $46 \cdot 00$ \\
\hline OCP48 & 49 & $59 \cdot 14$ & 1.41 & & 53.06 \\
\hline OCP52 & 49 & $70 \cdot 57$ & $1 \cdot 39$ & & $55 \cdot 10$ \\
\hline OCP44 & 50 & $71 \cdot 52$ & $1 \cdot 12$ & & 38.00 \\
\hline OCP25 & 50 & $90 \cdot 30$ & $1 \cdot 12$ & & $38 \cdot 00$ \\
\hline PB1 ${ }^{12}$ & 462 & $92 \cdot 42$ & 1.39 & & $28 \cdot 57$ \\
\hline $\mathrm{PH} 2 \mathrm{~b}^{24}$ & 307 & $100 \cdot 60$ & $1 \cdot 14$ & & 48.86 \\
\hline OCP27 & 49 & $103 \cdot 51$ & 1.57 & & $57 \cdot 14$ \\
\hline OCP24 & 49 & 114.79 & 1.66 & & 48.98 \\
\hline OCP51 & 49 & $120 \cdot 16$ & 2.57 & & 51.02 \\
\hline $\mathrm{PH} 3 \mathrm{~b}^{12}$ & 177 & 250.69 & $2 \cdot 39$ & & $39 \cdot 55$ \\
\hline $\mathrm{PH} 3 \mathrm{~b}^{24}$ & 40 & $352 \cdot 00$ & 1.73 & & $55 \cdot 00$ \\
\hline
\end{tabular}

* See Table 1 for type of mean used.

All fiies engorged upon the legs of the volunteers. DD: De León \& Duke (1966), BA: Bain (1971), PB: Philippon \& Bain (1972) (Subject: Maurice Tiemba, Léraba, raw data provided by Dr Odile Bain), PH: Philippon (1977) (Subjects 3b and 6 from Samandéni, $2 b$ from Léraba), OCP: Onchocerciasis Control Programme (data from Alley et al. 1994).

$\dagger^{12}$ Flies dissected up to $12 \mathrm{~h}$ p.e. ${ }^{24}$ Flies dissected at $24 \mathrm{~h}$ p.e. All flies from OCP dissected between 4 and 10 h p.e. 
Table 5. Successful larvae of Onchocerca volvulus from different microfilarial intakes by Simulium guianense in Southern Venezuelan Amazonas

\begin{tabular}{|c|c|c|c|c|c|c|}
\hline \multirow{2}{*}{$\begin{array}{l}\text { Study } \\
\text { participants } \\
\text { Patient } \\
\text { code no. } †\end{array}$} & \multicolumn{5}{|c|}{ Mean no. of larvae/fly* } & \multirow{2}{*}{$\begin{array}{l}\text { Prevalence } \\
\text { of flies with } \\
\text { successful } \\
\text { larvae } \\
(\%)\end{array}$} \\
\hline & $\begin{array}{l}\text { No. of } \\
\text { flies }\end{array}$ & $\begin{array}{l}\text { Ingested } \\
\text { mff } \\
(x)\end{array}$ & $\begin{array}{l}\text { Thoracic } \\
\text { mff } \\
(y)\end{array}$ & $\begin{array}{l}\text { No. of } \\
\text { flies }\end{array}$ & $\begin{array}{l}\text { L3 } \\
\text { larvae } \\
(y)\end{array}$ & \\
\hline Coy-IIa ${ }^{6}$ & 9 & $1 \cdot 61$ & 0.00 & - & - & 0.00 \\
\hline David-a ${ }^{6}$ & 30 & $4 \cdot 12$ & $0 \cdot 10$ & - & - & $3 \cdot 33$ \\
\hline Joonafesi ${ }^{5}$ & 10 & $4 \cdot 62$ & - & 11 & 0.46 & $18 \cdot 18$ \\
\hline Cipriano $^{5}$ & 10 & $4 \cdot 78$ & - & 10 & 0.67 & $40 \cdot 00$ \\
\hline Coy $-I^{4}$ & 18 & $8 \cdot 32$ & $0 \cdot 24$ & - & - & $16 \cdot 67$ \\
\hline David-b 5 & 19 & $12 \cdot 77$ & - & 55 & $1 \cdot 01$ & $40 \cdot 00$ \\
\hline Coy-IIb & 17 & $21 \cdot 54$ & $0 \cdot 70$ & - & - & 35.29 \\
\hline Cecilio- $\mathbf{a}^{3}$ & 9 & $43 \cdot 00$ & - & 15 & 1.69 & $46 \cdot 67$ \\
\hline Cecilio-b ${ }^{4}$ & 13 & $57 \cdot 91$ & - & 37 & $1 \cdot 27$ & $37 \cdot 84$ \\
\hline Mayuba $^{5}$ & 10 & $58 \cdot 01$ & - & 22 & $1 \cdot 04$ & $54 \cdot 55$ \\
\hline Coy-III ${ }^{4}$ & 15 & $83 \cdot 33$ & 0.93 & - & 一 & $60 \cdot 00$ \\
\hline Cecilio-c $c^{5}$ & 10 & $85 \cdot 00$ & - & 46 & $1 \cdot 17$ & $41 \cdot 30$ \\
\hline Coy-IV ${ }^{4}$ & 31 & $114 \cdot 95$ & 1.09 & - & - & $61 \cdot 29$ \\
\hline David-c ${ }^{4}$ & 31 & $123 \cdot 15$ & $1 \cdot 33$ & - & - & 41.94 \\
\hline David-e ${ }^{2}$ & 26 & $165 \cdot 76$ & $1 \cdot 11$ & - & - & $46 \cdot 15$ \\
\hline David-f $\mathrm{f}^{3}$ & 11 & 253.05 & - & 13 & 1.60 & $46 \cdot 15$ \\
\hline
\end{tabular}

* See Table 1 for type of mean used.

$\uparrow$ Body regions on which flies were fed as follows:

${ }^{2}$ Back, ${ }^{3}$ Iliac zone, ${ }^{4}$ Buttocks, ${ }^{5}$ Calves, ${ }^{6}$ Ankles.

David-b and David-f from Takaoka et al. $(1984 b)$. All other volunteers from this work.

means of the likelihood ratio statistic, which is approximately chi-squared distributed with degrees of freedom equal to the difference between the number of parameters in the models being tested (Sokal \& Rohlf, 1981 ; Cox \& Oakes, 1984; Armitage \& Berry, 1987). The fitting procedure was then repeated with $k$ as a function of microfilarial intake.

\section{RESULTS}

Tables 2, 3, 4 and 5 summarize, respectively, the data sets from Guatemala, Northern Brazil, West Africa and South Venezuela.

The examination of raw scatter plots of the mean numbers of successful larvae against mean intakes for the S. ochraceum s.l., S. damnosum s.l. and $S$. guianense data sets revealed that in the 3 blackfly species the output of successful larvae tended to reach a plateau as the input of $\mathrm{mff}$ increased. As a consequence, the relationship between mean number of successful larvae $(y)$ and mean microfilarial intake $(x)$ was explored by fitting the model $y(x)=$ $a x /(1+c x)$ to all 3 data sets. This function takes the value of zero when no $\mathrm{mff}$ are ingested, describes an initially linear relationship with slope $a$ for very small values of $x$, and encompasses a process of density-dependent saturation in the number of larvae that can successfully develop within the fly (limitation), where $c$ is a measure of the strength of density dependence. Under the null hypothesis ( $c=$ 0 ) the model represents a linear relationship (proportionality) between the two variables in question. However, the initial shape of this relationship appeared to be non-linear in S. ochraceum s.l. when compared with that in S. damnosum s.l. and $S$. guianense. There was a slower and initially exponential increase in the numbers of successful larvae harboured by the Guatemalan simuliid, as opposed to a steeper and convex rise in the African and Venezuelan flies.

In order to test the hypothesis that the initial shape of the relationship between larval output and microfilarial input could be related to the presence or absence of a well-developed cibarial armature in the simuliid foregut, an independent data set, describing the proportion of injured parasites found in bloodmeals with varying microfilarial densities taken up by $S$. ochraceum s.l. (Bain, Durette-Desset \& De León, 1974) was analysed. This proportion was observed to decrease with increasing microfilarial intake up to a certain level (approximately up to $40 \%$ ). This density-dependent reduction of the rupture of ingested parasites by the cibarial teeth could translate into an initially increasing proportion of viable mff capable of migrating out of the abdomen 


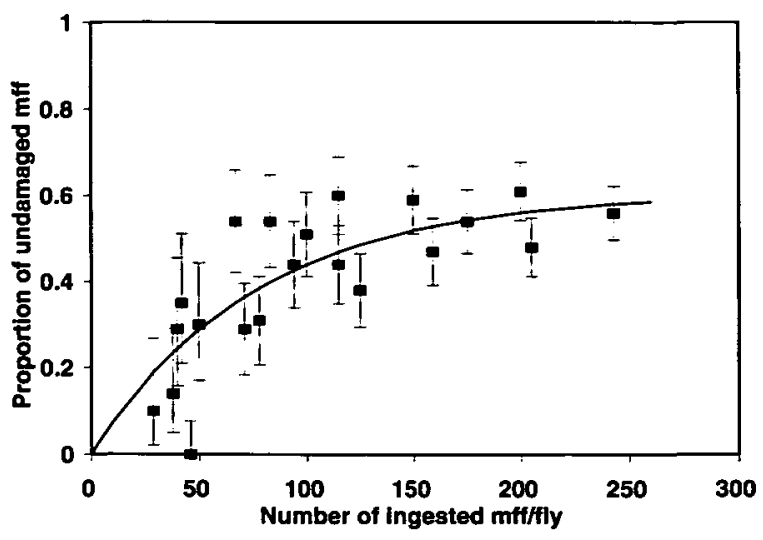

Fig. 1. Scatter plot of the proportion of unscathed microfilariae found in bloodmeals of Guatemalan Simulium ochraceum s.l. containing increasing numbers of $\mathrm{mff}$. The line is the non-linear regression fit obtained when the function $z=\alpha(1-\exp (-\beta x))$ was applied to the data points. $z$ is the fraction of uninjured parasites and $x$ the parasite intake. Parameter values are shown in Table 6. Data from Bain, Durette-Desset \& De León (1974). The $95 \%$ confidence intervals around the observed proportions, $p$, were calculated using the exact method based on the $F$ distribution for small values of $x(p x<20)$ and by the normal approximation $(p \pm 1.96$ $\sqrt{p(1-p) / x}$ for larger values of $x(p x \geqslant 20)$ (Armitage $\&$ Berry, 1985).

Table 6. Results of the non-linear model fitted to the data of Fig. 1 describing the fraction $(z)$ of ingested $\mathrm{mff}$ that remain unscathed by the cibarial armature of Simulium ochraceum s.l. as a function of parasite intake $(x)$ (Data from Bain, DuretteDesset \& De León (1974).)

\begin{tabular}{lc}
\hline \hline Model & $z=\alpha(1-\exp (-\beta x))^{*}$ \\
\hline$n$ & 21 \\
Correlation & 0.7917 \\
Proportion of variance explained & 0.6268 \\
$\alpha$ & 0.6071 \\
S.E. $(\alpha)$ & 0.0756 \\
$t(n-2)$ & 8.0313 \\
$P$ & 0.0000 \\
$\beta$ & 0.0129 \\
S.E. $(\beta)$ & 0.0036 \\
$t(n-2)$ & 3.5273 \\
$P$ & 0.0022 \\
\hline \hline
\end{tabular}

* $z$ is the expected proportion of intact $m f f$ in the bloodmeal containing $x$ ingested parasites. $\alpha$ is the maximum fraction of unscathed parasites to be attained. The parameter $\beta$ is a measure of the sensitivity to density dependence in the relationship between microfilarial intake and damage by the cibarial armature.

(initial 'facilitation'), that would be compatible with the pattern observed in the Guatemalan blackfly. As a result, the function $z=\alpha\left(1-\mathrm{e}^{-\beta x}\right)$, describing the expected fraction of unscathed mff, was fitted to the data of Bain (op. cit.) plotted as the fraction of $\mathrm{mff}$ remaining undamaged by the cibarial armature on their way to the stomach of the insects (Fig. 1). In
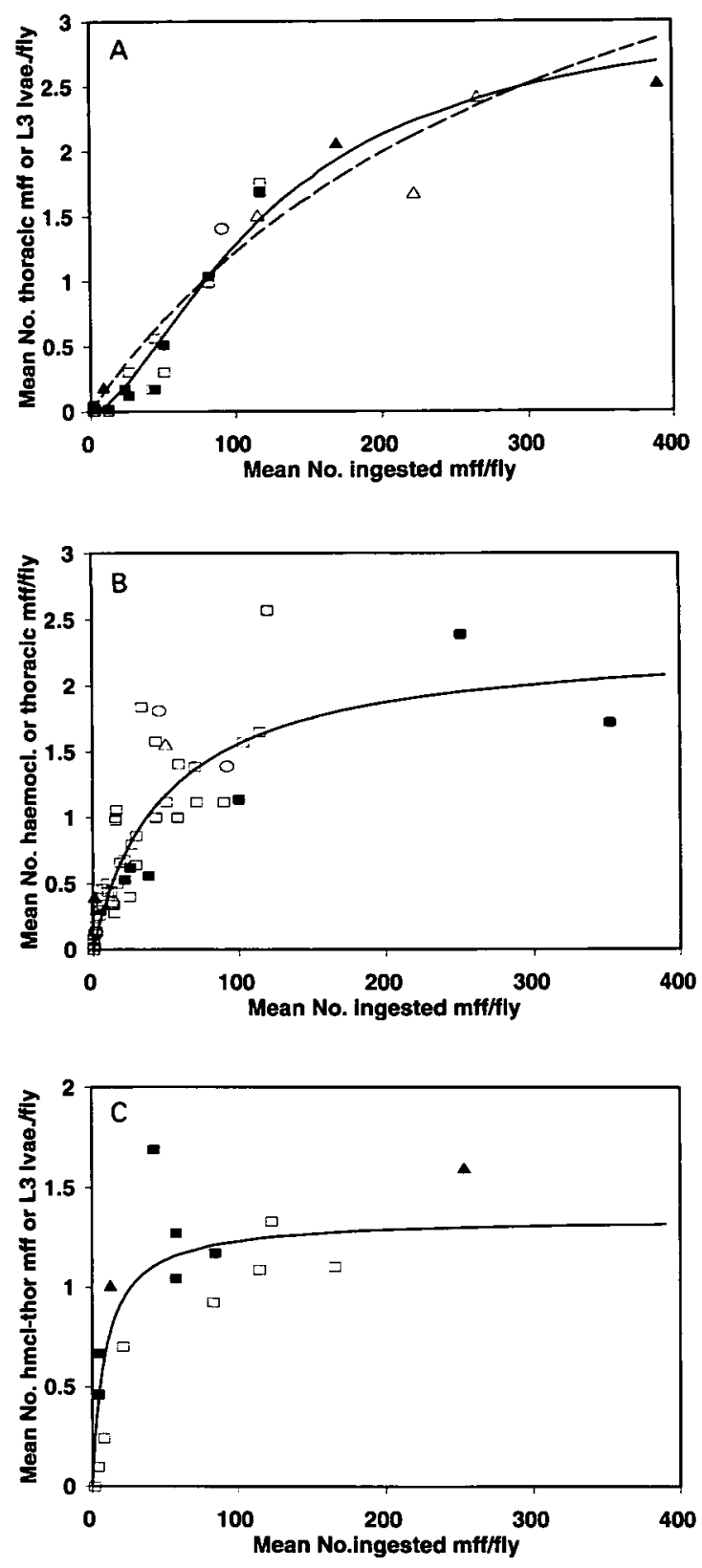

Fig. 2. (A) Scatter plot of the mean numbers of successful larvae (measured as mff escaping from imprisonment by the peritrophic membrane or developing to the infective stage) versus the mean microfilarial intake for Simulium ochraceum s.l. from Guatemala. The dotted line corresponds to the limitation model $y=a x /(1+c x)$, whilst the solid line corresponds to the expression $y=a \alpha(1-\exp (-\beta x))$ $x /(1+c x)$, where $y$ is the mean number of successful parasites and $x$ the mean microfilarial intake. The parameter values for the hyperbolic function are: $a=$ $0.0159 \pm 0.0017, c=0.0030 \pm 0.0007, a / c$ (saturation level) $=5.3352, r=0.95$. The parameter values for the sigmoid equation are presented in Table 7. Data points as follows: (A) L3 larvae, De León \& Duke (1966); $(\triangle)$ haemocoelic mff, Bain, Durette-Desset \& De León (1974); (O) thoracic mff, Omar \& Garms (1975);

(घ) L3 larvae and ( $\square$ ) thoracic mff, Collins et al. (1977). (B) Scatter plot of the mean numbers of successful larvae versus the mean microfilarial intake for $S$. damnosum s.s./S. sirbanum from West Africa. The fitted 
Table 7. Results of non-linear regression and correlation analyses of the mean number of successful larvae on mean microfilarial intakes for three Onchocerca volvulus-Simulium spp. combinations

\begin{tabular}{|c|c|c|c|}
\hline \multirow[b]{2}{*}{ Cibarial armature } & S. ochraceum s.l. & $\begin{array}{l}\text { Vector species } \\
\text { S. damnosum s.l. }\end{array}$ & S. guianense \\
\hline & Present & \multicolumn{2}{|c|}{ Absent } \\
\hline Model & $y=\frac{a \alpha\left(1-\mathrm{e}^{-\beta x}\right) x}{(1+c x)}$ & \multicolumn{2}{|c|}{$y=\frac{a x}{(1+c x)}$} \\
\hline$n$ & 27 & 54 & 16 \\
\hline Correlation & $\begin{array}{l}0.9730^{1} \\
0.9732^{2}\end{array}$ & 0.8740 & 0.8517 \\
\hline $\begin{array}{l}\text { Proportion of } \\
\text { variance explained }\end{array}$ & $\begin{array}{l}0.9468^{1} \\
0.9471^{2}\end{array}$ & 0.7639 & 0.7255 \\
\hline$a^{1}$ & 0.0612 & 0.0463 & $0 \cdot 1406$ \\
\hline S.E. $(a)$ & 0.0079 & 0.0097 & 0.0452 \\
\hline$t(n-2)$ & $7 \cdot 7817$ & $4 \cdot 7563$ & $3 \cdot 1079$ \\
\hline$P$ & 0.0000 & 0.0000 & 0.0077 \\
\hline$c^{1}$ & $0 \cdot 0112$ & 0.0196 & $0 \cdot 1040$ \\
\hline S.E. $(c)$ & 0.0020 & 0.0067 & 0.0389 \\
\hline$t(n-2)$ & $5 \cdot 5002$ & 2.9521 & $2 \cdot 6725$ \\
\hline$P$ & $0 \cdot 0000$ & 0.0047 & 0.0182 \\
\hline$a^{\prime}=a \alpha^{1}$ & 0.0372 & & \\
\hline$\beta$ & 0.0129 & & \\
\hline$a^{\prime 2}$ & 0.0339 & & \\
\hline S.E. $\left(a^{\prime}\right)$ & 0.0098 & & \\
\hline$t(n-3)$ & $3 \cdot 4718$ & & \\
\hline$P$ & 0.0020 & & \\
\hline$\beta^{2}$ & 0.0139 & & \\
\hline S.E. $(\beta)$ & 0.0034 & & \\
\hline$t^{\prime}(n-3)$ & $4 \cdot 1375$ & & \\
\hline$P$ & 0.0004 & & \\
\hline$c^{2}$ & 0.0100 & & \\
\hline S.E. $(c)$ & 0.0034 & & \\
\hline$t(n-3)$ & $2 \cdot 7202$ & & \\
\hline$P$ & 0.0119 & & \\
\hline
\end{tabular}

1 The sigmoid model corresponding to the $S$. ochraceum s.l. data was fitted using the parameter values for $\alpha$ and $\beta$ already estimated from the data shown in Fig. 1 and Table $6, \alpha=0.6071$ and $\beta=0.0129$.

2 The model for $S$. ochraceum s.l. was fitted estimating all three parameters $a^{\prime}=$ $a \alpha, \beta$ and $c$ from the data set shown in Fig. 2A and Table 2.

this expression $\beta$ is a measure of the degree of density-dependent decrease in the damage to ingested $\mathrm{mff}$ caused by the cibarial armature of the vector and $\alpha$ is the maximum proportion of parasites left uninjured as intake increases. When $\beta=0$, all

model is the equation $y=a x /(1+c x)$, where $y$ and $x$ have been defined in (A). Parameter values are given in Table 7. (A) L3 larvae, De León \& Duke (1966); ( $\triangle$ ) haemocoelic mff, Bain (1971); (O) haemocoelic mff, Philippon \& Bain (1972); ( $\mathbb{0}$ ) haemocoelic mff, Philippon (1977); ( $\square$ ) exo-peritrophic mff, Alley et al. (1994). (C) Scatter plot of the mean numbers of successful larvae versus mean microfilarial intake for $S$. guianense from South Venezuela. The line corresponds to the expression $y=a x /(1+c x)$ fitted to the data points. Parameter values are indicated in Table 7 . L3 larvae, Takaoka et al. (1984b); (ロ) L3 larvae and ( $\square)$ thoracic $\mathrm{mff}$, this work. ingested parasites are lesioned $(z=0)$. When $\beta \rightarrow \infty$, a constant, density-independent proportion of $\mathrm{mff}$ is left unscathed $(z=\alpha)$. The fitting of the model to the data of Fig. 1 provided a value of $\beta$ which was small but significantly different from zero (Table 6), suggesting the existence of a certain degree of protection against cibarial damage dependent on the density of microfilarial intake. Since under the null hypothesis of no facilitation, $z=\alpha$ for all values of $x$, the existence of initial non-linearity was tested by plotting the $95 \%$ confidence limits around the observed proportions of undamaged $\mathrm{mff}$ in Fig. 1. It can be seen that for the lower values of parasite intake the confidence intervals do not include the estimated value of $\alpha=0.6071 \quad(95 \% \quad$ C.L. $=$ $0.4489-0.7653$ ), supporting the hypothesis of initial facilitation. The expression for $z$ was thus incorporated into the hyperbolic function previously described in order to obtain an alternative model for 

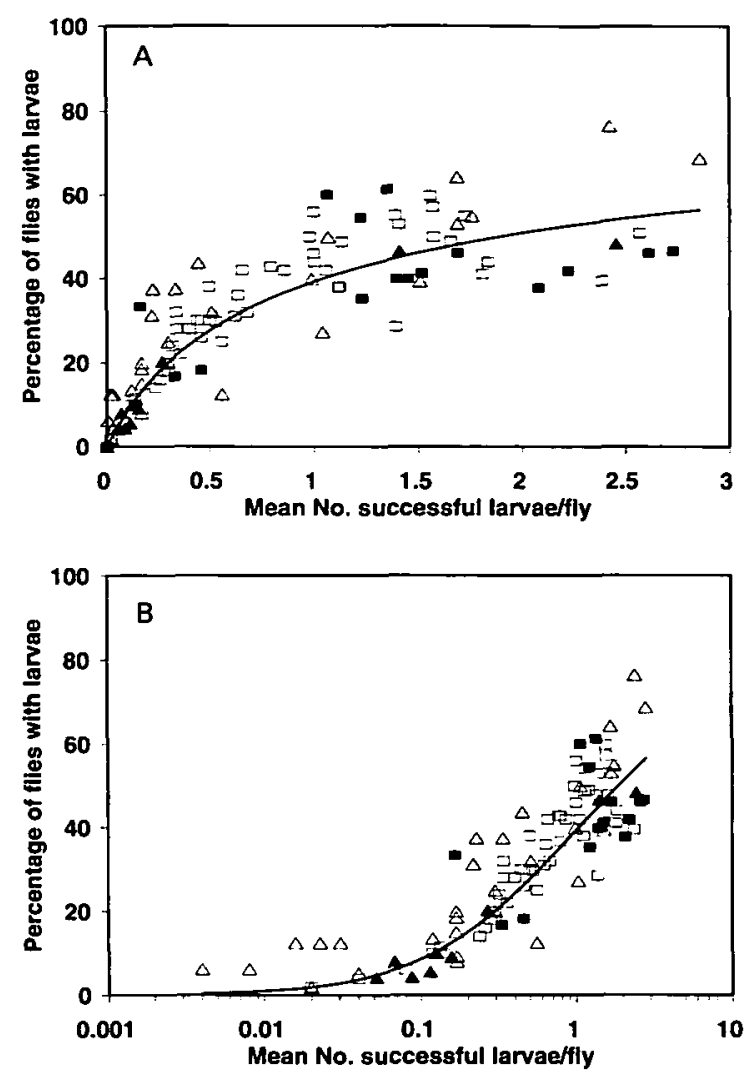

Fig. 3. (A) Scatter plot of the percentage of flies harbouring successful larvae versus the mean larval load per fly for all simuliid species included in this study. The line is the maximum likelihood fit applied to this prevalence versus intensity data set assuming the relationship in equation (1): proportion of potential or realized infective flies $=1-[1+y / k]^{-k}$, where $y$ is the mean number of successful larvae and $k$ an inverse measure of the degree of larval aggregation $(k=0.3950$, see text): Data points are: $(\triangle)$ Simulium ochraceum s.l.;

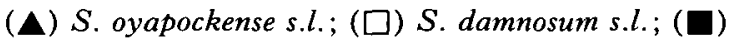
$S$. guianense. (B) Percentage of flies with successful larvae plotted against the logarithm of the mean number of larvae per insect. Line and data points are as described in (A).

S. ochraceum s.l., in which $y(x)=a \alpha\left(1-\mathrm{e}^{-\beta x}\right)$ $x /(1+c x)$. The inclusion of a positive feed-back operating at low densities in otherwise hyperbolic expressions has led to satisfactory sigmoid fittings of observed functional responses in other biological situations (Hassell, Lawton \& Beddington, 1977).

Two approaches were taken to estimate the parameters of the sigmoid model fitted to the Guatemalan blackfly. In the former, the values of the parameters $\alpha$ and $\beta$, obtained from the fit applied to the data shown in Fig. 1, were fed into the alternative equation describing the relationship between successful and ingested larvae for $S$. ochraceum s.l., whilst in the latter, all the parameters in this equation were freely estimated from the data set depicted in Fig. 2A. The proportion of the variance explained by the hyperbolic limitation model was then compared with that resulting from the sigmoid function including initial facilitation.

The scatter plots of the data points corresponding to $S$. ochraceum s.l., S. damnosum s.l. and S. guianense, and the curves fitted to them are shown respectively in Fig. $2 \mathrm{~A}, \mathrm{~B}$ and $\mathrm{C}$. A visual inspection of the curves in Fig. $2 \mathrm{~A}$ suggests that the sigmoid function confers a better fit to the Guatemalan data set than the hyperbolic expression. The proportion of the variation accounted for by the limitation model alone $(0.9024)$, did increase when the expression for facilitation was added to the function $(0.9468$ in the case of $\alpha$ and $\beta$ being estimated from Fig. 1, and 0.9471 when all parameter values were computed from Fig. 2A). In addition, a better behaviour of the residuals was observed with the sigmoid function, and the fitting of the hyperbolic equation to $S$. ochraceum s.l. provided an upper limit of 5.34 successful larvae per fly, well in excess of observed values. As a consequence, we concentrated on the model with initial facilitation for S. ochraceum s.l. and with limitation alone for S. damnosum s.l. and $S$. guianense. These models, the parameter values, and associated statistics are presented in Table 7. It can be seen that for $S$. ochraceum s.l., the two procedures used to fit the sigmoid model provided very similar results. The $95 \%$ C.L. around the parameter $\beta$ were $0.0052-0.0205$ and $0.0070-0.0209$ in each case.

The crucial test for detecting density-dependent limitation of the numbers of larvae that succeed in developing within the 3 blackfly species, in the framework of the chosen functions, depends on the parameter $c$ being significantly greater than zero. The $95 \%$ confidence intervals around this parameter did not include zero in any of the data sets examined. The limits were $0.0063-0.0330$ for S. damnosum s.l. and $0.0205-0.1875$ for $S$. guianense. In the sigmoid models fitted to $S$. ochraceum s.l. the values were: $0 \cdot 0070-0.0153$ when the information derived from Fig. 1 was used, and $0.0024-0.0175$ when all the parameters of the proposed equation were estimated from the data points in Fig. 2A. The fitted expressions predict a maximum number of larvae equal to $a / c$ in the case of $S$. damnosum s.l. $(2 \cdot 35)$ and $S$. guianense $(1 \cdot 35)$ and equal to $a . \alpha / c$ for $S$.ochraceum s.l. $(3 \cdot 32)$.

Fig. 3A and B show the percentage of simuliids carrying successful larvae plotted against the mean larval burden per fly in arithmetic and logarithmic scales, respectively, for all blackfly species included in this study. The line is the maximum likelihood fit to these data using the relationship in equation (1) with $k$ independent of the mean larval load $(y)$. The fit provided an estimate of $k=0.3950$ with $95 \%$ asymptotic confidence limits $=0 \cdot 3579-0 \cdot 4367$. The likelihood ratio statistic showed no significant difference between the model with constant $k$ and those with $k$ as a linear $(k(y)=\delta+\phi y)$, power $\left(k(y)=\delta y^{\phi}\right)$ 

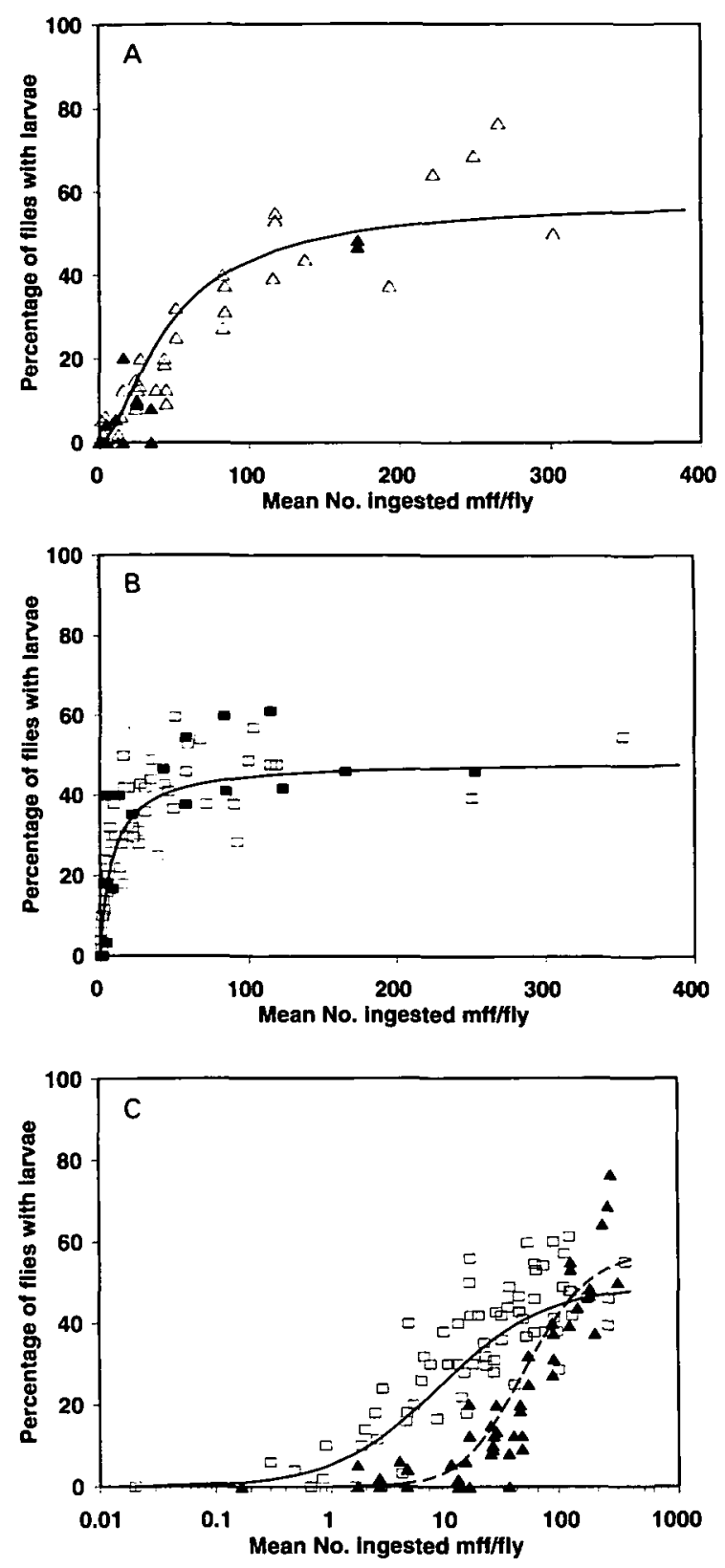

Fig. 4. (A) Percentage of flies with successful larvae plotted against mean microfilarial intake in simuliid species possessing a well-developed cibarial armature. The line was obtained by applying equation (2): proportion of infective flies $=1-[1+y(x) / k]^{-k}$, where $y$ (the mean no. of successful larvae) is a function of $x$ (parasite intake). The function is described in Fig. 2(A); (solid line); parameter values are those for Simulium ochraceum s.l. (Table 7), and $k$ value is that of Fig. 3 .

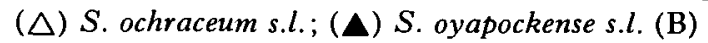
Percentage of flies with successful larvae versus mean microfilarial intake in simuliid species with unarmed cibarium. Line as described in (A) where $y(x)$ follows the expression in Fig. 2B and C. Parameter values are those for $S$. damnosum s.l. (Table 7) and $k$ value is that of Fig. 3. ( $\square$ ) S. damnosum s.l.; ( $\square$ ) S. guianense. (C) Percentage of flies with successful larvae plotted against the logarithm of the mean parasite intake in armed and unarmed blackflies. The logarithmic scale permits a better appreciation of the difference between both kinds of vectors particularly at low microfilarial intakes. and exponential $\left(k(y)=\delta \mathrm{e}^{\phi y}\right)$ function of the mean worm burden per fly, so the results of these models are not presented. A common value of $k$ was computed to measure the degree of aggregation of potentially or realized infective larvae in both armed and unarmed simuliids. Our argument in favour of a common $k$ was based upon the fact that this parasite stage has already evaded the effect of the cibarial armature when present, and also because a shared $k$ value provided a better description of the proportion of flies with successful larvae as a function of the mean microfilarial intake per fly (see below). The low value of $k$ suggests a high degree of larval aggregation which was also observed in the distributions fitted to the direct larval counts per insect. The latter did not depart significantly from the negative binomial when tested with the goodness of fit chi-squared test (data not shown). The average $k$ in this case was 0.3334 , ranging from 0.1811 to 0.5381 , in agreement with the value estimated from equation (1).

The values of $k$ thus obtained were used to fit the relationship between the percentage of infective flies and the mean microfilarial intake $(x)$ by means of equation (2) and the sigmoid expression $y(x)=$ $a \alpha\left(1-\mathrm{e}^{-\beta x}\right) x /(1+c x)$ for the species with cibarial armature (S. ochraceum s.l. and S. oyapockense s.l., Fig. 4A), whilst equation (2) plus the hyperbolic function $y(x)=a x /(1+c x)$ were used for the unarmed species ( $S$. damnosum s.l. and $S$. guianense, Fig. $4 B$ ). In the case of the data set combining the species with cibarial teeth, the parameter values of $y(x)$ were those of $S$. ochraceum s.l. For the data concerning the species without armature the parameter values of $S$. damnosum s.l. were chosen (the figures estimated for $S$. guianense tended to underestimate the proportion of infective flies). Fig. $4 \mathrm{C}$ compares on a logarithmic scale the data and fitted lines of the percentage of flies with successful larvae as the numbers of $\mathrm{mff}$ ingested increase in the armed and unarmed simuliids. This proportion increased more slowly and tended to level off between 50 and $60 \%$ for flies ingesting more than $150 \mathrm{mff}$ on average in the former group of flies, whilst the increase was faster and the maximum (between 40 and $50 \%$ ) reached earlier (intakes of $50 \mathrm{mff}$ upwards) in the latter group.

\section{DISCUSSION}

Basáñez et al. (1994) found little evidence of density dependence in the acquisition of skin microfilariae by flies feeding on $O$. volvulus carriers in 3 different endemic areas where $S$. ochraceum s.l., S. damnosum

Dotted line is as described in (A) solid line as in (B). (A) Simuliids with cibarial armature; $(\square)$ simuliids without armature. 
s.l. and S. guianense were the predominant vectors. The evidence for density dependence seems to be stronger when the fate of the ingested parasites is examined in the same blackfly species. The mean numbers of larvae succeeding in reaching the thoracic muscles of the flies and undergoing larval development to the infective stage reached a plateau of about 1-3 larvae per fly in the 3 simuliid species. This non-linearity was statistically significant in all data sets examined. Limitation had already been demonstrated in S. damnosum s.l. (Pichon, 1974; Bain, 1976; Boussinesq, 1991) but not studied in detail in any other blackflies. Apart from speciesspecific differences in vector competence, the lower saturation value found for $S$. guianense may be due to the fact that, in general, the Venezuelan flies dissected in order to detect thoracic mff were examined probably too early (average time ranging from $1 \cdot 15$ to $5 \cdot 11 \mathrm{~h}$ p.e.), with the result of lowered larval loads being observed. The Guatemalan and West African specimens were dissected between 4 and $10 \mathrm{~h}$ p.e., when most, if not all, microfilarial migration would have taken place (Laurence, 1966; Philippon, 1977). This conjecture finds some support in the better description of the relationship between the proportion of flies with larvae versus mean intake which was achieved when the parameter values obtained for the African species were used instead of those derived from the Venezuelan simuliid in equation (2).

The numerical investigation of the patterns of limitation, facilitation and proportionality occurring in several vectors of human and animal filariases has, so far, been based upon the statistical examination of the relationship between the so-called 'parasite yield' (ratio of successful larvae to microfilarial intake, $y / x)$, or the inverse of the parasite yield $(x / y)$, and the microfilarial intake $(x)$. In species with limitation $y / x$ tends to decrease with $x$ and there is a linearly increasing relationship between $x / y$ and $x$. The opposite is to be expected in species with facilitation. Proportionality translates into either the parasite yield or its inverse being independent of $x$ (Pichon, 1974; Prod'hon et al. 1980; Southgate \& Bryan, 1992). However, since the variable $x$ appears in both axes, the interpretation of the trends followed by the above-mentioned ratios is not necessarily straightforward on statistical grounds alone (Dr C. Dye, personal communication). Another, more general consideration to be taken into account when drawing conclusions about the patterns emerging from the analyses of variables that constitute mean values, is that a great deal of the variation in the data sets explored may be concealed, i.e. both the average number of successful larvae and the mean microfilarial intake per fly are subject to random variation.

The hyperbolic function fitted to the African data set is simpler than the empirical models previously used by Alley et al. (1994), Pichon (1974), and
Plaisier et al. (1991), yet it fits the data well and the estimation of the saturation level (around 2-3 larvae per fly) is very similar. The more complex functional form of the relationship between microfilarial input and infective larval output advocated by Plaisier $e t$ al. (1991) was found, however, to be necessary to allow those authors to explore the dynamics of recrudescence after cessation of vector control and the impact of ivermectin on transmission at low dermal parasite loads (Alley et al. 1994).

The results of the feeding studies analysed here, in which a single bloodmeal was provided at the beginning of the experiment, indicate that the average numbers of $\mathrm{mff}$ that reach the haemocoele or the thorax of the insects are generally good predictors of the numbers of L3 larvae to be found in the flies once the extrinsic incubation period is completed. This suggests that there is probably little larval loss during intra-thoracic development in susceptible flies, as has previously been reported by other authors (Duke, $1962 a$; Collins et al. 1977; Philippon, 1977). However, comparative analyses with natural infection rates and larval burdens are necessary. On the one hand, naturally infected females will have had the opportunity to ingest blood more than once (it has been shown that Onchocerca larval development is dependent on blood intake, Ham \& Gale (1984)), but also will have experienced some larval loss through feeding (Duke, 1973; Philippon, 1977; Renz, 1987) and different survival rates. On the other hand, these analyses could also throw some light on the relevance of possible mechanisms of acquired resistance by the biting fly population in natural settings. Until now, the presence of such mechanisms has only been demonstrated in experimental Onchocerca-Simulium systems based on intra-thoracic inoculation of $\mathrm{mff}$ (Ham, 1986, 1992), although there is an early observation describing that in wild host-seeking females, the presence of a previous infection in the fly seems to reduce the number of parasites that can develop from a subsequent infection (Duke, 1968).

The most important regulatory processes directly affecting Onchocerca survival and establishment within the flies (i.e. not considering indirect effects such as parasite-induced vector mortality), seem to be taking place early in the parasitic phase that occurs in the vector, namely, during the migration of the mff out of the mid-gut. The peritrophic membrane, which is secreted in response to the ingestion of blood, has been considered to act as an effective barrier to microfilarial migration in simuliids (Lewis, 1950, 1953; Duke \& Lewis, 1964; Bain \& Philippon, 1969; Reid \& Lehane, 1984; Eichner et al. 1991). However, the evidence is scarce and the mechanisms remain largely unknown. Bain et al. (1976) have proposed that density-dependent changes in the thickness and rate of formation of the peritrophic membrane may explain the limitation observed in 
the numbers of ingested parasites that gain access to the thoracic muscles in savanna members of the $S$. damnosum complex. Other possible explanations include the activation of insect defences, such as the lectin-like molecules acting at the level of the midgut epithelium that have been claimed to interfere with microfilarial migration in other filaria-culicid systems (Phiri \& Ham, 1990). This activation may be dependent on the density of the microfilariae.

The hypothesis that the level of saturation found in the system Onchocerca-Simulium is the result of processes acting early upon microfilarial migration rather than of some 'crowding effect' due to the overcoming of a larval carrying capacity, as described in other filaria-vector combinations such as Wuchereria-Aedes (Rosen, 1955) and BrugiaMansonia (Wharton, 1957 $a, b$ ), is supported by the results of experimental injections of mff directly into the thorax of the flies. This procedure permits the circumvention of the barriers associated with the infection per os and has resulted in the demonstration of a nearly proportional relationship between larval output and microfilarial input in intrinsically susceptible flies (Lok et al. 1980; Ham \& Bianco, 1983; Eichner et al. 1991).

Although limitation, acting at high parasite intakes, was common to the 3 blackfly species studied (expressed in the term $1 /(1+c x)$ of the models fitted and in the statistical significance of the parameter $c$ ), the pattern of initial exponential increase in the numbers of $\mathrm{mff}$ reaching the haemocoele or thorax of the flies present in the Guatemalan data set, is more compatible with initial 'facilitation'. Bain et al. (1974) interpreted their data on S. ochraceum s.l., plotted on logarithmic scales on both $y$ and $x$ axes, as evidence of proportionality. Our analysis suggests that density-dependent damage of the ingested $\mathrm{mff}$ by the cibarial armature in $S$. ochraceum s.l. may produce an initial positive feed-back between microfilarial intake and the number of parasites which are viable and hence capable of migrating out of the bloodmeal.

The hypothesis of an association between the presence of a cibarial armature in the insect host and the pattern of initial facilitation requires further investigation in other filaria-vector combinations. So far, the causal mechanism that has been claimed to operate in relation to facilitation involves histological changes in the abdominal epithelium (Bain \& Brengues, 1972). However, it is interesting to note that facilitation has solely been reported for vectors possessing cibarial teeth, such as Anopheles mosquitoes of the subgenus Cellia (McGreevy et al. 1978), including $A n$. gambiae s.s., An. arabiensis and $A n$. funestus (Brengues \& Bain, 1972; Southgate \& Bryan, 1992), although the statistical evidence for its demonstration in some of these cases has recently been questioned (Dye, 1994). Table 8 summarizes the patterns reported in the literature for several vector-filaria combinations concerning the relationship between microfilarial input and larval output. It can be seen that only limitation or proportionality have been described for vectors with poorly developed armatures or totally unarmed cibaria (Culex, Aedes, Mansonia, S. damnosum s.l.).

A possible explanation for the decline in the proportion of ingested $\mathrm{mff}$ that are injured by the cibarial armature as intake increases, is that it may be more likely for a few mff all to be ruptured by the teeth as they are pumped in with the bloodmeal, whilst as more larvae are ingested, the ones that become entangled may protect the remainder. A similar decrease in the fraction of ingested parasites ruptured by the cibarial teeth has been found in Wuchereria bancrofti-An. funestus, but not in $W$. bancrofti-An. gambiae s.l. (Bryan \& Southgate, 1988; Bryan, McMahon \& Barnes, 1990).

Although the proportion of the variance in the Guatemalan data explained by the function incorporating density-dependent damage by the cibarial armature of $S$. ochraceum s.l. is very high, we can only suggest that this mechanism may contribute to the pattern observed without the exclusion of other possible underlying processes. More probably, the phenomena of 'facilitation' and 'limitation' are the result of the combination of a variety of factors whose net effect is still to be elucidated. Among others, these factors include the interaction of the ingested $\mathrm{mff}$ with the cibarial teeth, with the peritrophic membrane, clotting agents and digestive enzymes acting in the bloodmeal, cellular reactions in the epithelium of the stomach, and insect defences (Denham \& McGreevy, 1977; Townson \& Chaithong, 1991). For example, Bryan et al. (1990) have reported that not all the undamaged mff of $W$. bancrofti observed in the bloodmeals of anopheline vectors in East Africa were able to reach the thoracic muscles of the mosquitoes.

The value of the clumping parameter $k$, obtained from the proportion of flies with successful larvae versus mean larval burden, indicates a high degree of larval aggregation in the insect host. The magnitude of this aggregation ( $k=0.395)$ appears to be greater than that computed for ingested mff by means of the same kind of analysis $(k=0 \cdot 588-0.632$, Basáñez et al. (1994)), reflecting the fact that not all the flies that ingest mff become subsequently infected with developing and developed larvae. This high degree of contagion is compatible with an overdispersed distribution such as the negative binomial which was found to be an adequate description of the distribution of the raw larval counts (data not shown). The trend towards a decline in the value of $k$ with increasing age of infection in the flies has also been observed when the negative binomial distribution has been fitted to the numbers of larvae per fly found in naturally infected $S$. damnosum s.l. populations (Cheke, Garms \& Kerner, 1982; Garms \& Cheke, 
Table 8. Patterns observed for the relationship between microfilarial input and larval output in several vector-filaria combinations

\begin{tabular}{|c|c|c|c|c|}
\hline Vector spp. & Parasite spp. & Pattern & $\begin{array}{c}\text { Cibarial } \\
\text { armature in the } \\
\text { vector }\end{array}$ & Reference \\
\hline & $\begin{array}{c}\text { Wuchereria } \\
\text { bancrofti }\end{array}$ & \multirow{8}{*}{ Limitation } & \multirow{6}{*}{ Absent } & $\begin{array}{c}\text { Bain (1971) } \\
\text { Brengues \& Bain } \\
\text { (1972); Pichon } \\
\text { (1974) }\end{array}$ \\
\hline Aedes aegypti & $\begin{array}{c}\text { Setaria } \\
\text { labiatopapillosa }\end{array}$ & & & $\begin{array}{c}\text { Bain (1971) } \\
\text { Bain \& Chabaud } \\
(1974)\end{array}$ \\
\hline & $\begin{array}{c}\text { Skrjabinofilaria } \\
\text { skrjabini }\end{array}$ & & & $\begin{array}{l}\text { Bain (1976) } \\
\text { Chabaud et al. } \\
\text { (1986) }\end{array}$ \\
\hline & $\begin{array}{c}\text { Dipetalonema } \\
\text { dessetae }\end{array}$ & & & Bain (1976) \\
\hline $\begin{array}{c}\text { Aedes } \\
\text { polynesiensis }\end{array}$ & W. bancrofti & & & $\begin{array}{l}\text { Rosen (1955) } \\
\text { Pichon (1974) }\end{array}$ \\
\hline Aedes togoi & Brugia malayi & & & $\begin{array}{l}\text { Southgate \& } \\
\text { Bryan (1992) }\end{array}$ \\
\hline $\begin{array}{c}\text { Culex } \\
\text { quinquefasciatus } \\
(=C \text {. pipiens } \\
\text { fatigans })\end{array}$ & $W$. bancrofti & & $\begin{array}{l}\text { Very poorly } \\
\text { developed }\end{array}$ & $\begin{array}{c}\text { Jordan \& Goatly } \\
(1962) \\
\text { Pichon (1974) } \\
\text { Southgate \& } \\
\text { Bryan (1992) }\end{array}$ \\
\hline $\begin{array}{c}\text { Simulium } \\
\text { damnosum s.l. }\end{array}$ & O. volvulus & & Absent & $\begin{array}{c}\text { Bain (1971) } \\
\text { Philippon \& } \\
\text { Bain (1972) } \\
\text { Pichon (1974) }\end{array}$ \\
\hline $\begin{array}{c}\text { Mansonia dives/ } \\
\text { bonneae } \\
(=M . \text { longipalpis })\end{array}$ & Brugia malayi & Proportionality & Absent & $\begin{array}{c}\text { Wharton (1957) } \\
\text { Southgate \& } \\
\text { Bryan (1992) }\end{array}$ \\
\hline $\begin{array}{l}\text { Anopheles gambiae } \\
\text { s.s. }\end{array}$ & $W$. bancrofti & Facilitation & Present & $\begin{array}{l}\text { Brengues \& } \\
\text { Bain (1972) } \\
\text { Southgate \& } \\
\text { Bryan (1992) }\end{array}$ \\
\hline $\begin{array}{c}\text { An. arabiensis } \\
\text { An. funestus }\end{array}$ & & & & $\begin{array}{l}\text { Southgate \& } \\
\text { Bryan (1992) }\end{array}$ \\
\hline
\end{tabular}

1985). The opposite, a lower degree of aggregation, is to be expected in the presence of densitydependent parasite-induced vector mortality (Anderson \& Gordon, 1982). However, this assumes that this process operates uniformly at all stages of larval development, lopping the tails of skewed distributions. We have evidence that Onchocercainduced Simulium mortality acts predominantly during the early phases of infection, i.e. during microfilarial ingestion. The aspects of densitydependent mortality of infected vectors and parasite aggregation, in both human and fly hosts, will be the subject of subsequent publications.

The non-linear regression models describing larval output as a function of microfilarial input in the cases of the simuliids with and without cibarial armature, were used together with this value of $k$ in order to investigate the relationship between the 
fraction of flies with successful larvae and the average microfilarial intake. The fits obtained appeared to be reasonable descriptions of the data in both cases. The sigmoid equation derived for the Guatemalan blackfly species seemed adequate to explain the data of S. ochraceum s.l. and S. oyapockense s.l., whilst the hyperbolic model was suitable for $S$. damnosum s.l. and $S$. guianense. The results show that simuliids with armed foreguts require higher average parasite intakes than those by unarmed species in order to acquire equivalent levels of effective infection, measured as mean larval burdens per fly and as percentage of flies with larvae. Nevertheless, these same indicators suggest an increased vectorial efficiency of the armed species over the species without armature at heavier microfilarial intakes, in agreement with the remarks made by Shelley (1988, 1991). These differences will be further explored in the light of parasite-induced vector mortalities elsewhere. Elevated fly mortalities, following the ingestion of large numbers of parasites, have been reported to affect the species without the 'protection' afforded by the cibarial teeth (Lewis, 1953; Duke, 1962 a, 1966; Omar \& Garms, 1977; Takaoka et al. $1984 b$ ), in contrast to the lower death rates recorded for species with toothed fore-guts (De León \& Duke, 1966; Collins et al. 1977; Takaoka et al. 1984a; Shelley et al. 1987). However, the amount of parasite-related vector loss which really takes place in endemic areas will depend on how frequent is the acquisition of high parasite intakes in the field.

In conclusion, our analyses suggest the existence of 'initial facilitation' in blackfly species like S. ochraceum s.l. and S. oyapockense s.l., and confirm the occurrence of 'limitation' in the savanna members of $S$. damnosum s.l.; the latter also being found in $S$. guianense. The sigmoid nature of the relationships depicted in Figs 2A and 4A, is compatible with previous claims that facilitation may provide a threshold for the interruption of transmission in areas where vector species with this pattern prevail (Pichon et al. 1974; Bain, 1976; Webber, 1991; Southgate \& Bryan, 1992). Given that microfilarial intakes are roughly proportional to skin loads (Campbell et al. 1980; Alley et al. 1994; Basáñez et al. 1994), it is possible to postulate that control campaigns based solely on the reduction of the parasite reservoir in the human host are likely to be more successful in foci where the principal vectors have cibarial armatures, whilst a combination of both, measures against the vector and against the parasite, may be necessary in endemic areas maintained by blackfly species without such armatures (Shelley, 1991, 1994). The results of ongoing chemotherapy programmes with the microfilaricide ivermectin seem to support this conjecture (Remme et al. 1990; Cupp, 1992).

However, any speculation on the existence of a transmission threshold must be based on formal stability analysis of dynamic models that explicitly incorporate the features described above in the equations for the parasite in the vector host, as well as reasonable assumptions about the processes affecting the parasite in the human host (Dye, 1994; Dye \& Williams, 1994). The existing onchocerciasis models have been constructed for the epidemiological situations arising in West and Central African savanna regions (with density-dependent limitation of the number of parasites developing in the flies (Dietz, 1982; Plaisier et al. 1990, 1991, Alley et al. 1994), or in forest areas (proportionality is assumed by Davies (1993)). A model for the Latin American scenarios is greatly needed and is currently being developed. The practical relevance of theoretical breakpoints in the complex life-cycles of helminth parasites has been shown to depend on the nature of the frequency distributions of the numbers of worms per definitive and intermediate host (Macdonald, 1965; May, 1977; Anderson, 1980). In the case of highly overdispersed distributions, the parasite intensities at which unstable equilibria occur (below which the system is driven to extinction), may be too low to have a meaningful epidemiological impact (Anderson \& May, 1985).

The non-linearities described above need to be evaluated in the context of most field situations, where overdispersion translates into only a few individuals of the host populations harbouring the parasite intensities at which density-dependent constraints are likely to play a role. This applies to $\mathrm{mff}$ in the skin of the human host (Basáñez \& Yarzábal, 1989; Boussinesq, 1991) as well as to larvae in the simuliid vector (Cheke et al. 1982; Garms \& Cheke, 1985; Renz, 1987; Wenk, 1991). The question of whether the events comprising the life-cycle of the nematode in the vector are occurring in parasite ranges where the relationships are practically linear, will be explored in a subsequent publication in the light of the frequency distributions of worm burdens per human and per vector host.

We thank the Director of OCP, Dr E. M. Samba, for allowing us to make use of the Asubende (Ghana) data set. M.G.B. is indebted to CONICIT of Venezuela (Consejo Nacional de Investigaciones Científicas y Tecnológicas), grant No. S1-1473 for financial support of the field work carried out among the Venezuelan Yanomami, and the British Council/FCO for a research training scholarship at Imperial College. G.F.M. is a Royal Society University Research Fellow. R.M.A. thanks the Wellcome Trust for financial support. Professor K. Dietz, Dr C. Dye, Dr B. A. Southgate and $\mathrm{Mr} \mathrm{J}$. Williams contributed with very helpful discussions. Dr Brian Williams provided statistical advice. We also thank $\mathrm{Dr} \mathrm{J}$. H. Bryan for permitting us to examine her raw data on microfilarial damage by Anopheles gambiae s.l. and An. funestus. The assistance of $\mathrm{H}$. Frontado, N. J. Villamizar, M. Bolívar, J. A. Gómez, I. Narbaiza, V. Park and H. Suzuki during the field work in Venezuela, and of the field staff of the Epidemiological Evaluation Unit and of the Vector Control Unit of OCP is gratefully acknowledged. 


\section{REFERENCES}

ALlEY, E. S., AgOUA, H., BISSAN, Y., DOUCOURE, K., PLAISIER, A. P., REMME, J. H. F. \& QILLÉVÉRÉ, D. (1994). Infectivity of Simulium damnosum s.s. and S. sirbanum in relation to intensity of onchocerciasis infection of the human host in Asubende, Ghana. Tropical Medicine and Parasitology (in the Press).

ANDERSON, R. M. (1980). The dynamics and control of direct life cycle helminth parasites. Lecture Notes in Biomathematics 39, 278-322.

ANDERSON, R. M. \& GORDON, D. M. (1982). Processes influencing the distribution of parasite numbers within host populations with special emphasis on parasite-induced host mortalities. Parasitology 85 , 373-98.

ANDERSON, R. M. \& MAY, R. M. (1985). Helminth infections of humans: mathematical models, population dynamics, and control. Advances in Parasitology 24, 1-101.

ANDERSON, R. M. \& MAY, R. M. (1991). Infectious Diseases of Humans. Dynamics and Control. Oxford: Oxford University Press.

ARMITAGE, P. \& BERRY, G. (1987). Statistical Methods in Medical Research. Oxford: Blackwell Scientific Publications.

BAIN, O. (1971). Transmission des filarioses. Limitation des passages des microfilaires ingérées vers l'hémocèle du vecteur; interprétation. Annales de Parasitologie (Paris) 46, 613-31.

BAIN, O. (1976). Traversée de la paroi stomacale du vecteur par les microfilaires: techniques d'étude utilisées, importance épidémiologique. Bulletin of the World Health Organization 54, 397-401.

BAIN, O. \& BRENgues, J. (1972). Transmission de la wuchereriose et de la sétariose bovine: étude histologique de la traversée de la paroi stomacale d'Anopheles gambiae A et d'Aedes aegypti par les microfilaires. Annales de Parasitologie (Paris) 47, 399-412.

BAIN, O., DURETTE-DESSET, M. C. \& DE LÉON, R. (1974). Onchocercose au Guatemala: l'ingestion des microfilaires par Simulium ochraceum et leur passage dans l'hémocèle de ce vecteur. Annales de Parasitologie (Paris) 49, 467-87

BAIN, O. \& PHILIPPON, B. (1969). Mécanisme du passage des microfilaires à travers la paroi stomacale du vecteur; son importance dans la transmission de l'onchocercose. Comptes Rendus de l'Académie Scientifique de Paris 269, 1081-3.

BAIN, O., PHILIPPON, B., SEChAN, Y. \& CASSONE, J. (1976). Corrélation entre le nombre de microfilaires ingérées et l'épaisseur de la membrane péritrophique du vecteur dans l'onchocercose de savane africaine. Comptes Rendus de l'Académie Scientifique de Paris 283, 391-2.

basáñez, M. G., boussinese, M., Prod'hon, J., frontado, H., Villamizar, N. J., MEDLEY, G. F. \& ANDERSON, R. M. (1994). Density-dependent processes in the transmission of human onchocerciasis: intensity of microfilariae in the skin and their uptake by the simuliid host. Parasitology 108, 115-27.

BASÁÑEZ, M. G. \& YARZÁBAL, L. (1989). Onchocerciasis in the Sierra Parima and Upper Orinoco regions,
Federal Territory of Amazonas, Venezuela. In Parasitic Diseases: Treatment and Control (ed. Miller, M. J. \& Love, E. J.), pp. 231-56. Boca Raton, FL: CRC Press.

BOUSSINESQ, M. (1991). Etude épidémiologique de l'onchocercose en zone de savane camerounaise. Effets d'un traitement de masse par l'invermectine. Ph.D. thesis, University of Montpellier II.

BREngues, J. \& BAIN, o. (1972). Passage des microfilaires de l'estomac vers l'hémocèle du vector dans les couples Wuchereria bancrofti-Anopheles gambiae A, $W$. bancrofti-Aedes aegypti et Setaria labiatopapillosa- $A$. aegypti. Cahiers O.R.S.T.O.M. série Entomologie médicale et Parasitologie 10, 235-49.

BRYAN, J. H., MCMAHON, P. \& BARNES, A. (1990). Factors affecting transmission of Wuchereria bancroft $i$ by anopheline mosquitoes. 3. Uptake and damage to ingested microfilariae by Anopheles gambiae, $A n$. arabiensis, $A n$. merus and $A n$. funestus in East Africa. Transactions of the Royal Society of Tropical Medicine and Hygiene 84, 265-8.

BRYAN, J. H. \& SOUTHGATE, B. A. (1988). Factors affecting transmission of Wuchereria bancrofti by anopheline mosquitoes. 1. Uptake of microfilariae. Transactions of the Royal Society of Tropical Medicine and Hygiene 82, 128-37.

CAMPBElL, C. C., COLlins, R. C., HUONG, A. Y. \& FIGUEROA-MARROQUIN, H. (1980). Quantitative aspects of the infection of Simulium ochraceum by Onchocerca volvulus: the relation of skin microfilarial density to vector infection. Tropenmedizin und Parasitologie 31 475-8.

Chabaud, A., BaIN, O., LANdAU, I. \& Petit, G. (1986). La transmission des parasites par vecteurs hématophages: richesse des phénomènes adaptatifs. La Vie des Sciences, Comptes rendus, série générale 3, 469-84

CHEKE, R. A., GARMS, R. \& KERNER, M. (1982). The fecundity of Simulium damnosum s.l. in northern Togo and infections with Onchocerca spp. Annals of Tropical Medicine and Parasitology 76, 561-8.

COLlins, R. C., CAMPBell, C. C., Wilton, D. P. \& NEWTON, L. (1977). Quantitative aspects of the infection of Simulium ochraceum by Onchocerca volvulus. Tropenmedizin und Parasitologie 28, 235-43.

COLUZZI, M. \& TRABUCCHI, R. (1968). Importanza dell' armatura bucco-faringea in Anopheles e Culex in relazione alle infezioni con Dirofilaria. Parassitologia $10,47-59$.

COX, D. R. \& HINKLEY, D. v. (1974). Theoretical Statistics. London: Chapman and Hall.

COX, D. R. \& OAKES, D. (1984). Analysis of Survival Data. London: Chapman and Hall.

CUPP, E. w. (1992). Treatment of onchocerciasis with Ivermectin in Central America. Parasitology Today 8, 212-14.

CURTIS, C. F. \& GRAVES, P. M. (1983). Genetic variation in the ability of insects to transmit filariae, trypanosomes and malarial parasites. Current Topics in Vector Research 1, 31-62.

Davies, J. B. (1993). Description of a computer model of forest onchocerciasis transmission and its application to field scenarios of vector control and chemotherapy. Annals of Tropical Medicine and Parasitology 87, 41-63. 
DAVIES, J. B., WEIDHAAS, D. E. \& HAILE, D. G. (1987). Models as aids to understanding onchocerciasis. In Black-flies: Ecology, Population Management and Annotated World List (ed. Kim, K. C. \& Merrit, R. W.), pp. 396-407. University Park and London: Pennsylvania State University.

DE LEÓN, J. \& DUKE, B. O. L. (1966). Experimental studies on the transmission of Guatemalan and West African strains of Onchocerca volvulus by Simulium ochraceum, $S$. metallicum and $S$. callidum. Transactions of the Royal Society of Tropical Medicine and Hygiene 60, 735-52.

DENHAM, D. A. \& MCGREEVY, P. B. (1977). Brugian filariasis: epidemiological and experimental studies. Advances in Parasitology 15, 243-309.

DIETz, K. (1982). The population dynamics of onchocerciasis. In Population Dynamics of Infectious Diseases (ed. Anderson, R. M.), pp. 209-41. London: Chapman and Hall.

DIETZ, к. (1988). Density-dependence in parasite transmission dynamics. Parasitology Today 4, 91-7.

DUKE, B. O. L. (1962a). Studies on factors influencing the transmission of onchocerciasis. I. The survival rate of Simulium damnosum under laboratory conditions and the effect upon it of Onchocerca volvulus. Annals of Tropical Medicine and Parasitology 56, 130-5.

DUKE, B. O. L. $(1962 b)$. Studies on factors influencing the transmission of onchocerciasis. II. The intake of Onchocerca volvulus microfilariae by Simulium damnosum and the survival of the parasites in the fly under laboratory conditions. Annals of Tropical Medicine and Parasitology 56, 255-63.

DUKE, B. O. L. (1966). Onchocerca-Simulium complexes. III. The survival of Simulium damnosum after high intakes of microfilariae of incompatible strains of Onchocerca volvulus and the survival of the parasite in the fly. Annals of Tropical Medicine and Parasitology 60, 495-500.

DUKE, B. O. L. (1968). Studies on factors influencing the transmission of onchocerciasis. V. The stages of Onchocerca volvulus in wild 'forest' Simulium damnosum, the fate of the parasites in the fly, and the age-distribution of the biting population. Annals of Tropical Medicine and Parasitology 62, 107-16.

DUKE, B. O. L. (1973). Studies on factors influencing the transmission of onchocerciasis. VIII. The escape of infective Onchocerca volvulus larvae from feeding 'forest' Simulium damnosum. Annals of Tropical Medicine and Parasitology 67, 95-9.

DUKE, B. O. L. \& LEWIS, D. J. (1964). Studies on factors influencing the transmission of onchocerciasis. III. Observations on the effect of the peritrophic membrane in limiting the development on Onchocerca volvulus microfilariae in Simulium damnosum. Annals of Tropical Medicine and Parasitology 58, 83-8.

DYE, C. $(1992 a)$. The analysis of parasite transmission by bloodsucking insects. Annual Review of Entomology 37, 1-19.

DYE, C. $(1992 b)$. Does facilitation imply a threshold for the eradication of lymphatic filariasis? Parasitology Today 8, 109-10.

DYE, C. (1994). The epidemiological context of vector control. Transactions of the Royal Society of Tropical Medicine and Hygiene 88, 132-5.
DYE, C. \& WILliams, B. G. (1994). Non-linearities in the dynamics of indirectly-transmitted infections (or, does having a vector make a difference?). In Ecology of Infectious Diseases in Natural Populations (ed. Dobson, A. \& Grenfell, B. T.). Cambridge: Isaac Newton Institute for Mathematical Sciences (in the Press).

EICHNER, M., RENZ, A., WAHL, G. \& ENYONG, P. (1991). Development of Onchocerca volvulus microfilariae injected into Simulium species from Cameroon. Medical and Veterinary Entomology 5, 293-7.

FigueroA, H., COLlins, R. C. \& KOZEK, W. J. (1977). Postprandial transportation and maintenance of Simulium ochraceum infected with Onchocerca volvulus. American Fournal of Tropical Medicine and Hygiene 26, 75-9.

GARMS, R. \& CHEKE, R. A. (1985). Infections with Onchocerca volvulus in different members of the Simulium damnosum complex in Togo and Benin. Zeitschrift für angewandte Zoologie 72, 479-95.

GUYATT, H. L., BUNDY, D. A. P., MEDLEY, G. F. \& GRENFELL, B. T. (1990). The relationship between the frequency distribution of Ascaris lumbricoides and the prevalence and intensity of infection in human communities. Parasitology 101, 139-43.

hairston, N. G. \& De Meillon, B. (1968). On the inefficiency of transmission of Wuchereria bancrofti from mosquito to human host. Bulletin of the World Health Organization 38, 935-41.

HAM, P. J. (1986). Acquired resistance to Onchocerca lienalis infections in Simulium ornatum Meigen and Simulium lineatum Meigen following passive transfer of haemolymph from previously infected simuliids (Diptera, Simuliidae). Parasitology 92, 269-77.

HAM, P. J. (1992). Immunity in haemotophagous insect vectors of parasitic infection. Advances in Disease Vector Research 9, 101-49.

HAM, P. J. \& BIANCO, A. E. (1983). Screening of some British Simuliids for susceptibility to experimental Onchocerca lienalis infection. Zeitschrift für Parasitenkunde 69, 765-72.

HAM, P. J. \& GALE, C. L. (1984). Blood meal enhanced Onchocerca development and its correlation with fecundity in laboratory reared blackflies (Diptera, Simuliidae). Tropenmedizin und Parasitologie 35, 212-16.

HASSELL, M. P., LAWTON, J. H. \& BEDdington, J. R. (1977). Sigmoid functional responses by invertebrate predators and parasitoids. Fournal of Animal Ecology 46, 249-62.

JORDAN, P. \& GOATLY, K. D. (1962). Bancroftian filariasis in Tanganyika: a quantitative study of the uptake, fate and development of microfilariae of Wuchereria bancrofti in Culex fatigans. Annals of Tropical Medicine and Parasitology 56, 173-87.

LAURENCE, B. R. (1966). Intake and migration of the microfilariae of Onchocerca volvulus (Leuckart) in Simulium damnosum Theobald. Fournal of Helminthology 40, 337-42.

LEWIS, D. J. (1950). A peritrophic membrane in Simulium. Nature, London 165, 978.

LEWIS, D. J. (1953). Simulium damnosum and its relation to onchocerciasis in the Anglo-Egyptian Sudan. Bulletin of Entomological Research 43, 597-644.

LOK, J. B., CUPP, E. W., BRAIDE, E. I. \& BERNARDO, M. J. (1980). The development of Onchocerca spp. in 
Simulium decorum Walker and Simulium pictipes Hagen. Tropenmedizin und Parasitologie 31, 498-506. MACDONALD, G. (1965). The dynamics of helminth infections, with special reference to schistosomes Transactions of the Royal Society of Tropical Medicine and Hygiene 59, 489-506.

MAY, R. M. (1977). Togetherness among schistosomes: its effects on the dynamics of the infection. Mathematical Biosciences 35, 301-43.

MCGREEVY, P. B., BRYAN, J. H., OOTHUMAN, P. \& KOLSTRUP, N. (1978). On the lethal effects of the cibarial and pharyngeal armatures of mosquitoes on microfilariae. Transactions of the Royal Society of Tropical Medicine and Hygiene 72, 361-8.

MILleR, N. \& LEHANE, M. J. (1993). Petritrophic membranes, cell surface molecules and parasite tropisms within arthropods. Parasitology Today 9 , 45-50.

OBIAMIWE, B. A. (1977). Relationship between microfilarial density, the number of microfilariae ingested by mosquitoes and the proportion of mosquitoes with larvae. Annals of Tropical Medicine and Parasitology 71, 491-500.

OMAR, M. S. \& GARMS, R. (1975). The fate and migration of microfilariae of a Guatemalan strain of Onchocerca volvulus in Simulium ochraceum and $S$. metallicum, and the role of the buccopharyneal armature in the destruction of microfilariae. Tropenmedizin und Parasitologie 26, 183-90.

OMAR, M. S. \& GARMS, R. (1977). Lethal damage to Simulium metallicum following high intakes of Onchocerca volvulus microfilariae in Guatemala. Tropenmedizin und Parasitologie 28, 109-19.

PHILIPPON, в. (1977). Etude de la transmission d'Onchocerca volvulus (Leuckart, 1893) (Nematoda, Onchocercidae) par Simulium damnosum Theobald, 1903 (Diptera, Simuliidae) en Afrique tropicale. Travaux et Documents de l'O.R.S.T.O.M. (Paris) No. 63.

PHIRI, J. \& HAM, P. J. (1990). Enhanced migration of Brugia pahangi microfilariae through the mosquito midgut following $N$-acetyl-D-glucosamine ingestion. Transactions of the Royal Society of Tropical Medicine and Hygiene 84, 462.

PICHON, G. (1974). Relations mathématiques entre le nombre des microfilaires ingérées et le nombre des parasites chez différents vecteurs naturelles ou expérimentaux de filarioses. Cahiers O.R.S.T.O.M. série Entomologie médicale et Parasitologie 12, 199-216. PIChon, G., PERrault, G. \& LAigret, J. (1974). Rendement parasitaire chez les vecteurs de filarioses. Bulletin of the World Health Organization 51, 517-24.

Plaisier, A. P., vaN OORTMARSSEN, G. J., HABbEMa, J. D. F., REMME, J. \& ALLEY, E. S. (1990). ONCHOSIM: a model and computer simulation program for the transmission and control of onchocerciasis. Computer Methods and Programs in Biomedicine 31, 43-56.

PLAISIER, A. P., vaN OORTMARSSEN, G. J., REMME, J., ALLEY, E. S., \& HABBEMA, J. D. F. (1991). The risk and dynamics of onchocerciasis recrudescence after cessation of vector control. Bulletin of the World Health Organization 69, 169-78.

PROD'HON, J., PICHON, G., RIVIÈre, F., DE JARDIN, J., GÉRY, M., DOUÉ, F., FAUGĖRe, C. \& VERNeUiL, M. P. (1980).
Étude quantitative de la réduction parasitaire stomacale chez les vecteurs de filarioses. Cahiers O.R.S.T.O.M. série Entomologie médicale et Parasitologie 18, 13-25.

REID, G. D. F. (1978). Cibarial armature of Simulium vectors of onchocerciasis. Transactions of the Royal Society of Tropical Medicine and Hygiene 72, 438.

REID, G. D. F. (1994). Structure and function of the cibarial armature in Simuliidae. Medical and Veterinary Entomology 8, 295-301.

REID, G. D. F. \& LEHANE, M. J. (1984). Peritrophic membrane formation in three temperate simuliids, Simulium ornatum, $S$. equinum and $S$. lineatum, with respect to the migration of onchocercal microfilariae. Annals of Tropical Medicine and Parasitology 78, 527-39.

REMME, J., DE SOLE, G., DADZIE, K. Y., ALLEY, E. S., BAKER, R. H. A., Habbema, J. D. F., Plaisier, A. P., vaN oortmarsSEN, G. J. \& SAMBA, E. M. (1990). Large scale ivermectin distribution and its epidemiological consequences. Acta Leidensia 59, 177-91.

RENZ, A. (1987). Studies on the dynamics of transmission of onchocerciasis in a Sudan-savanna area of North Cameroon. III. Infection rates of the Simulium vectors and Onchocerca volvulus transmission potentials. Annals of Tropical Medicine and Parasitology 81, 239-52.

ROSEN, L. (1955). Observations on the epidemiology of human filariasis in French Oceania. American fournal of Hygiene 61, 219-48.

SHELLEY, A. J. (1988). Vector aspects of the epidemiology of onchocerciasis in Latin America. Annual Review of Entomology 30, 337-66.

SHELLEY, A. J. (1991). Simuliidae and the transmission and control of human onchocerciasis in Latin America. Cadernos de Saude Pública, RF 7, 310-27.

SHELlEY, A. J. (1994). Factors affecting filarial transmission by simuliids. Advances in Disease Vector Research 10, 183-214.

Shelley, A. J., Luna dias, A. P. A., Moraes, M. A. P. \& PROCUNIER, w. s. (1987). The status of Simulium oyapockense and $S$. limbatum as vectors of human onchocerciasis in Brazilian Amazonia. Medical and Veterinary Entomology 1, 219-34.

SOKAL, R. R. \& ROHLF, F. J. (1981). Biometry. The Principles and Practice of Statistics in Biological Research. New York: W. H. Freeman and Company.

SOUTHGate, B. A. \& BRYAN, J. H. (1992). Factors affecting transmission of Wuchereria bancrofti by anopheline mosquitoes. 4. Facilitation, limitation, proportionality and their epidemiological significance. Transactions of the Royal Society of Tropical Medicine and Hygiene 86 , 523-30.

SPIELMAN, A. \& ROSSIGNOL, P. A. (1985). Insect vectors. In Tropical and Geographical Medicine (ed.

Mahumoud, A. \& Warren, K.), pp. 172-5. Singapore:

McGraw Hill International Student Edition.

TAKAOKa, H., OCHOA, J. O., JUAREZ, E. L. \& HANSEN, K. M. (1982). Effects of temperature on development of Onchocerca volvulus in Simulium ochraceum, and longevity of the simuliid vector. Fournal of Parasitology 68, 478-83.

TAKAOKA, H., SLZCKI, H., NODA, S., OCHOA, J. O. \& TADA, I. 
$(1984 a)$. The intake, migration and development of Onchocerca volvulus microfilariae in Simulium haematopotum in Guatemala. Fapanese fournal of Sanitary Zoology 35, 121-7.

TAKAOKA, H., SUZUKI, H., NODA, S., TADA, I., BASÁÑEZ, M. G. \& YARZÁBAL, L. $(1984 b)$. Development of Onchocerca volvulus larvae in Simulium pintoi in the Amazonas region of Venezuela. American Fournal of Tropical Medicine and Hygiene 33, 414-19.

Townson, H. \& CHAITHONG, U. (1991). Mosquito host influences on development of filariae. Annals of Tropical Medicine and Parasitology 85, 149-63. WEBBER, R. H. (1991). Can anopheline-transmitted filariasis be eradicated? Yournal of Tropical Medicine and Hygiene 94, 241-4.

WENK, P. (1991). The vector host link in filariasis. Annals of Tropical Medicine and Parasitology 85, 139-47.

WHARTON, R. H. (1957a). Studies on filariasis in Malaya: observations on the development of Wuchereria malayi in Mansonia (Mansonioides) longipalpis. Annals of Tropical Medicine and Parasitology 51, 278-96.

WHARTON, R. H. (1957b). Studies on filariasis in Malaya: the efficiency of Mansonia longipalpis as an experimental vector of Wuchereria malayi. Annals of Tropical Medicine and Parasitology 51, 422-39. 